\title{
Comparative endocrinology of aging and longevity regulation
}

\section{John B. Allard and Cunming Duan*}

Department of Molecular, Cellular, and Developmental Biology, University of Michigan, Ann Arbor, MI, USA

\section{Edited by:}

Vance Trudeau, University of Ottawa,

Canada

\section{Reviewed by:}

Anderson O. L. Wong, The University of Hong Kong, Hong Kong

Mark Sheridan, North Dakota State

University, USA

*Correspondence:

Cunming Duan, Department of

Molecular, Cellular, and

Developmental Biology, University of Michigan, Natural Science Building,

Ann Arbor, MI 48109, USA.

e-mail:cduan@umich.edu
Hormones regulate growth, development, metabolism, and other complex processes in multicellular animals. For many years it has been suggested that hormones may also influence the rate of the aging process. Aging is a multifactorial process that causes biological systems to break down and cease to function in adult organisms as time passes, eventually leading to death. The exact underlying causes of the aging process remain a topic for debate, and clues that may shed light on these causes are eagerly sought after. In the last two decades, gene mutations that result in delayed aging and extended longevity have been discovered, and many of the affected genes have been components of endocrine signaling pathways. In this review we summarize the current knowledge on the roles of endocrine signaling in the regulation of aging and longevity in various animals. We begin by discussing the notion that conserved systems, including endocrine signaling pathways, "regulate" the aging process. Findings from the major model organisms: worms, flies, and rodents, are then outlined. Unique lessons from studies of non-traditional models: bees, salmon, and naked mole rats, are also discussed. Finally, we summarize the endocrinology of aging in humans, including changes in hormone levels with age, and the involvement of hormones in aging-related diseases. The most well studied and widely conserved endocrine pathway that affects aging is the insulin/insulin-like growth factor system. Mutations in genes of this pathway increase the lifespan of worms, flies, and mice. Population genetic evidence also suggests this pathway's involvement in human aging. Other hormones including steroids have been linked to aging only in a subset of the models studied. Because of the value of comparative studies, it is suggested that the aging field could benefit from adoption of additional model organisms.

Keywords: aging, longevity, lifespan, senescence, hormone, signaling, endocrine, insulin-like growth factor

\section{INTRODUCTION}

Aging is the process of progressive decline in the biological functions of cells and organs that causes most organisms to suffer from exponentially increasing mortality rates over time. The exact underlying causes of aging at the cellular level remain obscure. The most popular theory has been the free-radical theory of aging put forward by Harman (1956). This theory suggests that reactive oxygen species produced by mitochondria as a result of normal metabolism cause irreversible damage to DNA and protein that accumulates over a lifetime, and eventually causes the breakdown of homeostasis. There is a large amount of correlative evidence supporting this theory. However, direct evidence for the free-radical theory of aging is still scarce. To date, there have been a number of in vivo studies using transgenic/knockout mice with alterations in a wide variety of genes that affect the levels of free-radicals or oxidative stress. So far, most of these genetic manipulations have failed to show an effect on lifespan (reviewed in Perez et al., 2009). Thus the search for the underlying mechanisms of aging continues.

In recent years, forward genetics studies have discovered gene mutations that result in delayed aging and extended longevity, and many of the affected genes are components of endocrine signaling pathways. In retrospect, this should not have been surprising in view of the fact that the extension of lifespan is a massively complex phenotype that likely requires varying pleiotropic actions in different tissue and cell types, and would have to be synchronized at the organismic level. The endocrine system is known to regulate metabolism, growth, and homeostasis throughout the body, and by comparison, it is logical that the various mechanisms that oppose the underlying aging process would also be under the control of hormonal signaling systems.

This review will focus on our current understanding of the roles that hormonal signaling plays in the regulation of longevity in animals. We concentrate on so-called "cell-non-autonomous" mechanisms of aging, in which aging-related changes at the cellular level are caused by signals released from other cells rather than by an intrinsic factor within the cell itself. It should be noted that the relevant literature on the comparative endocrinology of aging is vast. We have attempted to focus on major endocrine signaling pathways that have been demonstrated to regulate longevity in order to paint a broad picture of the current state of the field. Throughout this article we refer to the concept of aging and longevity being "regulated." This is not intended to signify a presumption that aging is "programmed," but rather that the rate of aging can be promoted and inhibited by various factors including endocrine signaling. 


\section{CONSERVED ROLES OF ENDOCRINE SIGNALING IN LONGEVITY REGULATION}

The role of the endocrine system in human aging was first proposed in the late 1800s by Charles-Édouard Brown-Séquard who has been called one of the fathers of endocrinology for his role in the demonstration that the adrenal glands produce hormones that are essential for life (Tattersall, 1994). Unfortunately, his attempts to extend his own life by subcutaneously injecting animal seminal fluid and testicular extracts were misguided, but they launched a fad in the early twentieth century of similar attempts to extend life (Haber, 2004). It is now known that in worms (Hsin and Kenyon, 1999), flies (Flatt et al., 2008), fish (Robertson, 1961), rats (Drori and Folman, 1976), and possibly humans (Hamilton and
Mestler, 1969), removal of the gonads (or germline in C. elegans) actually extends lifespan. These findings may indicate a conserved role of gonadal hormones in longevity regulation, but a hormone involved in mediating this effect has so far been identified only in C. elegans (Yamawaki et al., 2010).

Direct evidence for the involvement of hormonal signaling in longevity came after the identification of the first single gene mutations in C. elegans that extended lifespan (Friedman and Johnson, 1988; Kenyon et al., 1993; Kimura et al., 1997). These were components of a widely conserved endocrine signaling pathway that is orthologous to the Insulin and Insulin-like growth factor Signaling pathways in mammals, and is therefore referred to as the "IIS pathway," (see Figure 1A). Mutations in genes encoding components

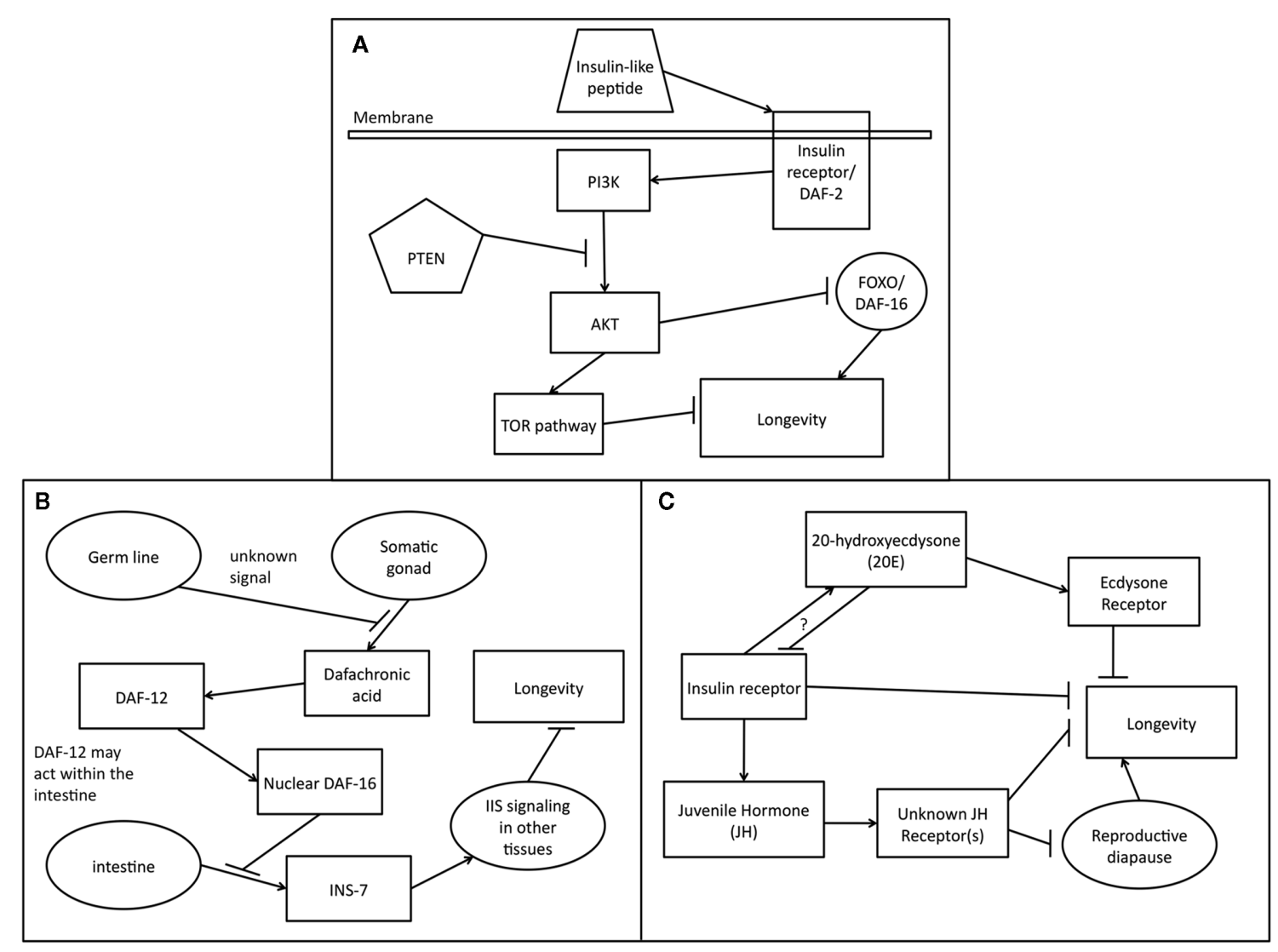

FIGURE 1 | Endocrine signaling pathways affecting longevity.

(A) Role of the conserved IIS signaling pathway in longevity regulation. Insulin-like peptides bind to an insulin/IGF receptor on the plasma membrane. Ligand binding causes dimerization of the receptor, activating the intracellular tyrosine kinase domain.

Phosphorylation by the receptor kinase domain activates the PI3 Kinase (PI3K). The signaling activity of PI3K, antagonized by the PTEN phosphatase, activates the Akt kinase. Akt phosphorylates FOXO/DAF-16 which is then sequestered in the cytosol. In the absence of IIS signaling, FOXO translocates to the nucleus and activates transcription of longevity promoting genes. AKT signaling also opposes longevity by activating the TOR pathway, which inhibits autophagy, a pro-longevity process. (B) Endocrine signaling in the $C$. elegans germline longevity pathway. The germ line stem cells send an unknown signal that allows other tissues to detect that they are present. When the germ line stem cells are ablated, the somatic gonad releases the steroid dafachronic acid that binds to the nuclear hormone receptor DAF-12. It is unclear exactly where DAF-12 acts to receive this signal but the intestine is a possible location. As a result of signaling via DAF-12, DAF-16/FOXO activity increases in the nuclei of intestinal cells. This in turn leads to signaling from the intestine to the other tissues that informs them about status of the DAF-16/FOXO in the intestine. INS-7 promotes IIS signaling which suppresses DAF-16/FOXO activity but DAF-16/FOXO in the intestine can down regulate the expression of INS-7 and this may be one mechanism by which intestinal DAF-16/FOXO controls other tissues. (C) Regulation of longevity by 20-hydroxyecdysone (20E) and juvenile hormone (JH) in insects. JH suppresses reproductive diapause which promotes longevity. JH may also negatively affect longevity in other ways. The receptor(s) to which $\mathrm{JH}$ binds is unknown. 20E activates the ecdysone receptor which may reduce longevity. IIS engages in cross talk with both $\mathrm{JH}$ and $20 \mathrm{E}$ and also reduces longevity via other signaling pathways. 
of this pathway in Drosophila were later found that also extended lifespan (Clancy et al., 2001; Tatar et al., 2001b). In mice, mutations that reduce the levels of insulin-like growth factor 1 (IGF-1) were shown to extend lifespan (Flurkey et al., 2001; Coschigano et al., 2003). Hypomorphic mutations in IIS pathway component genes in humans also have been associated with extended longevity (Suh et al., 2008; Tazearslan et al., 2011). The conserved role of the IIS pathway in longevity regulation is a central theme in the comparative endocrinology of aging.

The conservation of molecular mechanisms that regulate longevity is suggested also by the effects of caloric restriction on lifespan in different animal species. It was observed in 1935 that rats fed fewer total calories while receiving sufficient vitamins and other nutrients to prevent malnutrition exhibited an extended lifespan (Mccay et al., 1935). Since then, this life-extending intervention has been tested and demonstrated to be effective in the major model systems C. elegans (Klass, 1977), Drosophila (Chapman and Partridge, 1996; Mair et al., 2003), and mice (Cheney et al., 1980), as well as in a diverse range of other species including spiders, rotifer, guppies, and many others (Comfort, 1963; Fanestil and Barrows, 1965; Austad, 1989). Caloric restriction seems to not only extend the duration of life but also the, "health span," or the period during which an animal remains free of aging-related diseases. This is demonstrated by the fact that caloric restriction delays a large number of aging-related diseases and conditions in rodents, monkeys, and humans, including cancer, cardiovascular disease (CVD), diabetes, sarcopenia, and immunosenescence, among others (Cheney et al., 1980; Weindruch and Walford, 1982; Weindruch et al., 1986; Black et al., 2003; Fontana et al., 2004; Messaoudi et al., 2006; Colman et al., 2008, 2009). Many different variations in the protocols of caloric restriction exist, and the methods used for different species differ. The exact effects and extent of longevity enhancement often vary depending on the strain and the different protocols used, and these effects have been reviewed extensively elsewhere. It is not surprising that the effects of caloric restriction would be complex given the complexity of the underlying aging process and its dependence on may different genes. Given this complexity, the nearly universal ability of caloric restriction to extend lifespan would seem to support the notion that it is regulated by conserved genetic mechanisms. The exact processes that mediate the effects of caloric restriction are still unclear.

A possible conserved role of endocrine signaling in longevity regulation is suggested by the fact that caloric restriction causes alterations in hormonal signaling levels in various species. In rodents, caloric restriction reduces insulin levels (Masoro et al., 1992) and IGF-1 levels (Breese et al., 1991; D’Costa et al., 1993), increases corticosterone levels (Sabatino et al., 1991), and decreases serum thyroid hormone levels (Herlihy et al., 1990). The effects on thyroid hormone, which regulates metabolic rate, would seem to suggest that a reduction in metabolic rate could be involved in extending lifespan, but energy expenditure in calorically restricted rats was found to be higher than expected based on body composition (Selman et al., 2005). Rats that stood in cool water for $4 \mathrm{~h}$ a day, 5 days a week throughout life consumed $44 \%$ more food than controls, but their longevity was not different despite their increased energy expenditure (Holloszy and Smith, 1986).
Drosophila also did not show reduced metabolic rate under caloric restriction (Hulbert et al., 2004). Metabolic rate was found to be uncorrelated with lifespan in an analysis of data from hundreds of species (De Magalhaes et al., 2007). Rather, age at sexual maturity was found to be positively correlated with lifespan, suggesting that factors that regulate growth and maturation may be connected with longevity regulation (Prothero, 1993; De Magalhaes et al., 2007).

In humans caloric restriction can also reduce serum IGF-1 levels, insulin levels, and the levels of sex steroids, in addition to other hormonal changes (see the section below on the endocrinology of human aging). Salutary effects of caloric restriction have been reported in humans, but any possible effects on lifespan have yet to be determined (reviewed in Fontana and Klein, 2007). In Drosophila, ablation of the cells in the nervous system that secrete insulin-like peptides (ILPs), called the median neurosecretory cells (mNSCs), resulted in the loss of most of the increased longevity caused by caloric restriction, indicating that the function of these cells is required for the extension of lifespan observed (Broughton et al., 2010). Mutation in the Drosophila insulin receptor substrate 1 (IRS-1) gene, chico, results in lower IIS signaling and increases lifespan, and subjection of these mutant flies to caloric restriction produced different effects depending on the amount of dietary restriction. The effects were consistent with the idea that the chico mutants were already subject to some of the same effects caused by dietary restriction, as mild dietary restriction could extend their lifespans but more severe restriction caused them to die sooner than controls (Clancy et al., 2002). This suggests overlap between the mechanisms of lifespan extension in caloric restriction and reduction in IIS signaling. In C. elegans however, caloric restriction by both reduction of food availability and mutations that reduce efficiency of the eating process, are independent of the IIS signaling pathway (Lakowski and Hekimi, 1998; Houthoofd et al., 2003). One way this was demonstrated was by showing that already long-lived mutants with reduced IIS signaling could be made to live even longer by caloric restriction. Long-lived Ames dwarf mice also live even longer when subjected to caloric restriction (Bartke et al., 2001), but, long-lived growth hormone receptor knockout mice do not (Bonkowski et al., 2009).

\section{ADVANCES IN THE ENDOCRINOLOGY OF AGING IN MODEL SYSTEMS}

In this section we discuss the major findings that relate to the endocrinology of aging in each of the major model organisms: C. elegans, Drosophila, and rodents. Both widely conserved and species-specific mechanisms have been discovered in each of these models, and by comparing the results from multiple organisms one can formulate better hypotheses regarding human aging (see Table 1).

\section{ELEGANS}

The first mutation found to extend lifespan in C. elegans was in the age-1 gene (Klass, 1983; Friedman and Johnson, 1988). This gene was shown to encode a homolog of PI3 kinase, which is a downstream component of the intracellular pathway that transduces signals from the IIS pathway (see Figure 1A). A later analysis found that second generation homozygous null age-1 mutant worms 
Table 1 | Characteristics of aging model organisms.

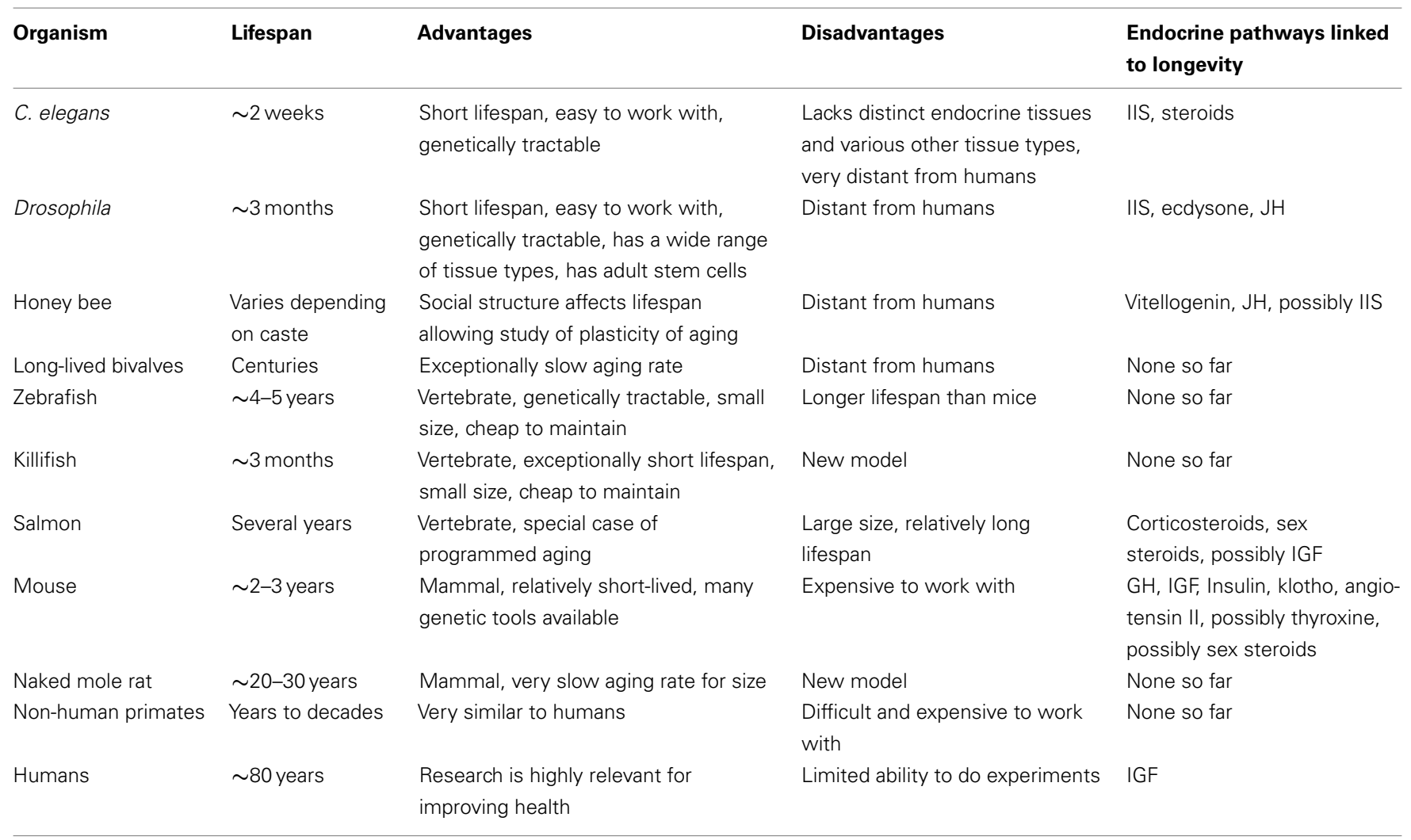

lived almost 10 times longer than wild type worms (Ayyadevara et al., 2008). Subsequently, mutations in various other components of this pathway were shown to be involved (Kenyon et al., 1993). Many of these mutants that exhibited long adult lifespans were so-called dauer formation mutants; that is, mutants with an altered tendency to enter the dauer larval state.

The C. elegans dauer larva is an alternative larval stage that can survive for months without feeding and is very resistant to stress (Cassada and Russell, 1975). Formation of dauer larvae is promoted by low nutrient availability in the environment, and also by high levels of a dauer pheromone produced by all individuals (Golden and Riddle, 1984). This stage allows the worms to survive until more food becomes available. Various dauer formation (daf) mutations have been found that either prevent dauer formation or cause constitutive dauer formation (Riddle et al., 1981). The observation has been that mutations that increase dauer formation tend to increase adult lifespan as well. The gene daf-2 is the C. elegans insulin receptor homolog and the major down stream effector of the pathway is daf-16, which is a FOXO family transcription factor that is required for the lifespan extension effects produced by mutation of daf- 2 and other pathway components (Kenyon et al., 1993; Kimura et al., 1997). Signaling through the IIS pathway leads to sequestration of DAF-16/FOXO in the cytosol, thereby suppressing its anti-aging activity (Figure 1A).

daf-2 mutant worms live two to three times longer than wild type worms. It is noteworthy that mosaic analysis showed that daf-2 mutation only in certain cells was capable of extending lifespan for the whole organism, indicating a cell-non-autonomous effect which may be mediated by endocrine signaling (Apfeld and Kenyon, 1998). Some but not all mutations in daf-2 cause reduced fecundity in addition to varying levels of lifespan extension, indicating lifespan can be decoupled from reduced reproductive costs (Gems et al., 1998). Furthermore it was shown that RNAi knockdown of daf-2 during development reduced fecundity but did not extend lifespan, whereas knockdown only during adulthood extended lifespan without affecting fecundity (Dillin et al., 2002). This indicates that the effects of IIS mutants on lifespan in the adult stage are actually dependent on the levels of IIS during adulthood, rather than "left over" longevity factors of some kind from the larval stage during which the dauer formation decision is made.

C. elegans has about 40 ILP genes in its genome (www.wormbase.org). It is thought that these ILPs functioned by binding to the receptor tyrosine kinase DAF-2 (Olinski et al., 2006). Some of these molecules function as DAF-2 receptor agonists while others were proposed to act as antagonists (Pierce et al., 2001; Li et al., 2003; Murphy et al., 2007). However, the functions of most of the ILPs remain unknown, and it is not clear whether all of them interact with DAF-2. Vertebrates have a subgroup of insulin-like molecules called the relaxin/insulin-like family that function by binding to $\mathrm{G}$ protein-coupled receptors (Hsu et al., 2002; Hoffmann and Opazo, 2011).

Other signaling pathways have been implicated in regulating aging in worms including transforming growth factor TGF $\beta$ signaling which seems to act partly through modulation of IIS signaling (Shaw et al., 2007; Narasimhan et al., 2011). Serotonin 
signaling was also shown to promote aging via an effect on the IIS pathway (Murakami and Murakami, 2007).

Of particular interest is the observation that signaling in certain specific tissues is required for longevity enhancement in a number of cases. Disabling sensory input to certain neurons can extend or reduce lifespan for the whole organism (Apfeld and Kenyon, 1999; Alcedo and Kenyon, 2004; Bishop and Guarente, 2007). daf-16 expression is normally required for lifespan extension in daf-2 mutants. Expression of daf-16 only in the intestine is sufficient to rescue the lifespan extension in long-lived daf-2 mutants that lack DAF-16/FOXO in other tissues (Libina et al., 2003). DAF-16 down-regulates expression of one of the ILPs, INS-7. INS-7 is a DAF-2 agonist, and when DAF-16 activity is increased in the intestine, it leads to increased DAF-16/FOXO activity throughout the body by reducing levels of INS-7 secreted by the intestine (Murphy et al., 2007). In long-lived daf-2 mutants, replacement of daf-2 only in neurons was found to reduce the lifespan to wild type levels (Wolkow et al., 2000). However the role of neuron-specific IIS was found to be minor in a later study (Libina et al., 2003). A mutation which alters mitochondrial function can extend lifespan even when present only in certain cells, indicating cell-non-autonomous functions even for a mutation affecting a fundamental metabolic process (Durieux et al., 2011).

Steroid hormones have also been shown to contribute to longevity regulation in C. elegans (Jia et al., 2002; Broue et al., 2007; Gerisch et al., 2007). Mutations of an enzyme involved in steroid hormone synthesis called DAF-9 extend lifespan, and this extension also requires a nuclear hormone receptor called DAF-12, but does not require DAF-16/FOXO (Jia et al., 2002). Long-lived daf-9 mutants are returned to normal lifespan by treatment with bile acid-like steroids called dafachronic acids (Gerisch et al., 2007), which are endogenous ligands of DAF-12 (Motola et al., 2006). These findings suggest that DAF-9 generates dafachronic acid, which promotes aging by interacting with DAF-12. In contrast, treatment with another steroid, called pregnenolone, which can be found in vertebrates, extended lifespan in worms, and this extension also required DAF-12 (Broue et al., 2007). Thus, steroid signaling via DAF-12 is capable of both promoting and opposing aging, and in fact, different mutations in daf-12 itself can either shorten or extend lifespan (Fisher and Lithgow, 2006). It is also noteworthy that null mutations of $d a f-12$ further extend the already long lifespans of strong daf-2 (insulin receptor) mutants, but they block the lifespan extension caused by weak daf-2 mutations (Gems et al., 1998).

When the $C$. elegans germline cells are ablated, lifespan is increased, and $d a f-9$ and $d a f-12$ are required for this effect, along with daf-16 (Hsin and Kenyon, 1999; Gerisch et al., 2001; ArantesOliveira et al., 2002). Removal of the entire gonad does not extend lifespan, and it was shown that the somatic gonad tissue, which expresses daf-9 (Gerisch et al., 2001), was required for the lifespan extension due to removal of the germline (Yamawaki et al., 2008). However, in already long-lived DAF-2 deficient worms, removal of the entire gonad extended lifespan even further, allowing them to live six times longer than wild type and remain healthy and active throughout most of this time (Arantes-Oliveira et al., 2003). This indicates that strong reduction in IIS signaling eliminates the need for the signal normally provided by the somatic gonad. The hormone responsible for this anti-aging signal has been identified as the steroid dafachronic acid, which binds to DAF-12 (Gerisch et al., 2007; Yamawaki et al., 2010). Germline removal causes DAF$16 /$ FOXO to accumulate in the nuclei of intestinal cells and this mediates the increase in lifespan (Lin et al., 2001; Libina et al., 2003). It is speculated that dafachronic acid released by the somatic gonad activates DAF-12 in the intestinal cells, which in turn enhances DAF-16 nuclear localization and promotes longevity by down-regulating intestinal secretion of INS-7, leading to lower IIS levels throughout the body (Figure 1B), but this has not yet been confirmed. The factors that determine whether DAF-12 promotes or opposes aging remain unknown. A gene called kri-1 and a transcription elongation factor caller TCER-1 are required for DAF-16 nuclear localization and transcriptional activity to be promoted by germline removal but not by IIS reduction (Berman and Kenyon, 2006; Ghazi et al., 2009). There is presumably another endocrine pathway that signals the presence or absence of the germ line to the rest of the body but this pathway has not yet been identified. Many other open questions exist regarding the roles of endocrine signaling in regulating longevity in response to germ line removal (reviewed in Kenyon, 2010).

\section{DROSOPHILA}

The fruit fly Drosophila has several advantages as a model for studying endocrinology of aging. Flies have several distinct endocrine glands and a wider range of tissue types in general than C. elegans. Also, unlike C. elegans which lack dividing somatic stem cells in the adult stage, Drosophila have now been shown to posses adult somatic stem cells in at least five different tissues (Margolis and Spradling, 1995; Micchelli and Perrimon, 2006; Ohlstein and Spradling, 2006; Singh et al., 2007, 2011; Voog et al., 2008).

IIS signaling regulates longevity in Drosophila. The Drosophila genome contains seven insulin-like peptide (dILP) genes and one insulin receptor (INR), and signaling through the INR by each of the dILPs promotes growth in flies (Brogiolo et al., 2001). The dILPs are expressed in different spatiotemporal patterns during development (Brogiolo et al., 2001). Three of the dILPs are produced and secreted by a collection of neurons called mNSCs and this secretion can be regulated by the availability of nutrients in larvae (Ikeya et al., 2002). Genetic ablation of the mNSCs slows growth and larval development, and increases lifespan (Rulifson et al., 2002; Broughton et al., 2005). Loss of the mNSCs also interferes with the lifespan extension resulting from caloric restriction by yeast dilution (Broughton et al., 2010). A null mutation of the gene encoding dILP2 extended lifespan but null mutations in the other dILP genes did not (Gronke et al., 2010). It is noteworthy that the developmental expression patterns of progenitors of the two tissues indicates homology between the mNSCs in flies and the insulin secreting pancreatic beta cells in vertebrates (Wang et al., 2007b).

Some hypomorphic mutations in the gene encoding the single INR were shown to extend female Drosophila lifespan by up to $85 \%$ while causing dwarfism and preventing maturation of the gonads (Tatar et al., 2001b). Mutations of many genes encoding components of the INR signaling pathway, such as the PI3K and AKT homologs, cause normal or reduced lifespan or are lethal, which is not surprising due to the important roles of this pathway 
in normal growth and development (Clancy et al., 2001). However, heterozygous and homozygous mutations in the IRS gene homolog, chico, extend fly lifespan (Clancy et al., 2001; Tu et al., 2002a). They can also further extend lifespan in long-lived female flies that also carry a mutation which prevents oogenesis, indicating that reduction of fertility is not the mechanism by which the longevity of chico mutants is extended (Clancy et al., 2001). Also, chico heterozygotes have normal size and normal fertility and are nevertheless longer-lived than wild type although not as long-lived as the homozygotes (Clancy et al., 2001).

As in C. elegans, several studies have demonstrated in Drosophila that tissue-specific modifications can extend the lifespan of the whole organism, indicating cell-non-autonomous effects that may be mediated by endocrine signaling. The transcription factor dFOXO is the Drosophila homolog of C. elegans DAF-16 and functions downstream in the IIS pathway (see Figure 1A). Overexpression of $\mathrm{dFOXO}$ in the head fat body (the equivalent of adipose tissue in mammals) during adulthood modulated expression of one of the ILPs and extended lifespan (Giannakou et al., 2004; Hwangbo et al., 2004). Overexpression of dFOXO in the head fat body only during the early adult period was found to be sufficient for increasing lifespan and did not adversely affect fecundity (Giannakou et al., 2007). Autophagy, or macroscopic cellular self-digestion, has been proposed as a cell-autonomous longevity mechanism. Increasing levels of autophagy only in the fly nervous system by overexpression of an autophagy protein increases fly lifespan by $50 \%$, indicating likely cell-non-autonomous effects on other tissues (Simonsen et al., 2008). Olfactory neuron signaling has also been shown to regulate lifespan in Drosophila (Libert et al., 2007).

Because caloric restriction and many lifespan-extending IIS mutations often result in reduced fecundity in various model systems, it has often been suggested that there is a trade-off between investment of energy in reproduction or in somatic maintenance (i.e., repairing mutations and damage etc.). In Drosophila, dietary restriction extends lifespan and reduces fecundity (Chapman and Partridge, 1996; Mair et al., 2003). However, it is frequently possible to decouple positive longevity effects from negative fecundity effects. When additional quantities of the amino acid methionine were provided to flies during dietary restriction, the fecundity was restored to the level of wild type flies without reducing the extension in lifespan caused by the reduced calorie intake (Grandison et al., 2009). In Drosophila, there is a cost of mating for females in that their lifespan is reduced by mating (Chapman and Partridge, 1996). If this were caused by transfer of resources from somatic maintenance to reproduction, then it would be expected that sterile females would have reduced costs of mating, but in fact it was found that their costs were increased (Ueyama and Fuyama, 2003). The cost of mating has been found to be mediated by a signaling molecule in male seminal fluid called sex peptide (Wigby and Chapman, 2005). Ablation of germ cells in flies has been found to extend lifespan (Flatt et al., 2008). Whether this effect is mediated by endocrine signaling as in C. elegans is currently unknown.

The phyla to which Drosophila and C. elegans belong, Arthropoda and Nematoda respectively, are both members of the superphylum ecdysozoa (Mallatt and Winchell, 2002; Dunn et al.,
2008). The most significant common feature that members of these phyla share is that during early development they periodically shed their cuticle or exoskeleton and produce a new larger one to accommodate continued growth. This process is termed ecdysis, and it gives the super phylum its name. Ecdysis is stimulated by a steroid hormone called 20-hydroxyecdysone $(20 \mathrm{E})$, which is the active form of a prohormone called ecdysone (Thummel, 1996; Nakagawa and Henrich, 2009). A group of hormones called juvenile hormones $(\mathrm{JH})$ that are sesquiterpenoid lipids also participate in the regulation of growth and development along with $20 \mathrm{E}$, and the presence or absence of $\mathrm{JH}$ is what determines whether a larva will undergo ecdysis or metamorphosis in response to 20E (reviewed in Dubrovsky, 2005).

Both $20 \mathrm{E}$ and $\mathrm{JH}$ regulate a wide variety of processes in insects, and they have been implicated in the regulation of adult longevity (Figure 1C). JH is secreted by a gland called the corpus allatum (Altaratz et al., 1991). Drosophila and some other insects can undergo so-called reproductive diapause during their adult stage, which in many ways resembles the dauer in C. elegans (Tatar et al., 2001a). In this condition, oogenesis and mating cease, stress resistance increases, metabolism decreases, and longevity is increased (Tatar et al., 2001a). Reductions in JH signaling control entry into diapause (Tatar, 2004). Treatment with a JH analog blocks diapause in Drosophila (Tatar et al., 2001a). When the corpus allatum is removed in other insects, their lifespan can be increased (Tatar and Yin, 2001). Removal of the corpus allatum in monarch butterflies that undergo reproductive diapause doubled longevity whereas injection with JH halved it (Herman and Tatar, 2001). Long-lived inr mutants have reduced JH signaling, and treatment with $\mathrm{JH}$ reduces their lifespan back to wild type levels (Tatar et al., 2001b; Tu et al., 2005). When fly larvae were treated with a JH analog their lifespan was reduced but early life fertility was increased (Flatt and Kawecki, 2007). Flies selected for 19 generations for survival in somewhat toxic levels of $\mathrm{JH}$ analog overcame some of the lifespan reduction; these flies were longerlived than wild type in the absence of JH (Flatt and Kawecki, 2007). The exact roles that JH plays in regulating aging are still being studied but the indications are that it promotes aging in insects.

Long-lived female inr mutants also have reduced 20E levels, which may be related to the fact that their ovaries are undeveloped, and the ovaries are the major site of $20 \mathrm{E}$ synthesis ( $\mathrm{Tu}$ et al., 2002b). The 20E and IIS signaling pathways engage in cross talk during growth and development (Colombani et al., 2005; Walkiewicz and Stern, 2009). Flies heterozygous for mutations in the ecdysone receptor have increased longevity with no negative effects on reproduction (Simon et al., 2003). A mutant involved in $20 \mathrm{E}$ biosynthesis also has increased longevity (Simon et al., 2003). A more recent study involving adult-specific inactivation of the ecdysone receptor by RNAi or dominant negatives found that there was a mild lifespan extension in males, but in females lifespan was decreased (Tricoire et al., 2009). This harmful effect was prevented in a sterile mutant (Tricoire et al., 2009). There are many interesting similarities between 20E signaling in flies and dafachronic acid signaling in worms that suggest that these are homologous pathways (reviewed in Galikova et al., 2011). 


\section{MICE AND RATS}

In vertebrates, the IIS signaling pathway has diverged into two distinct pathways, those of insulin and IGFs. Mammals have three IIS ligands, insulin, IGF-1, and IGF-2, and an insulin receptor and IGF-1 receptor (IGF-1R; reviewed in Taguchi and White, 2008). Insulin regulates metabolism, and IGF regulates development, growth, cell survival, proliferation, and other effects. IGF-1 is secreted by the liver in response to growth hormone from the anterior pituitary gland; signaling by IGF-1 is responsible for the growth-promoting effects of growth hormone (Liu and Leroith, 1999). IGF-1 is also secreted by peripheral tissues and this pool of IGF-1 can compensate for the loss of liver-derived IGF-1, which normally accounts for most of the IGF-1 in the serum (Yakar et al., 1999). IGF-1R signaling is essential for postnatal survival in mice, making it difficult to study using knockouts (Liu et al., 1993).

The observation that caloric restriction in rats increased lifespan was followed by work showing that pituitary hormone secretion was inhibited during this state (Mccay et al., 1935; Mulinos and Pomerantz, 1940). It was later demonstrated that removal of the pituitary gland retarded some effects of aging (Everitt and Cavanagh, 1965; Olsen and Everitt, 1965). The Snell and Ames dwarf mice that have mutations in transcription factors (Pit-1 and Prop-1) that prevent the normal development of the anterior pituitary were discovered many decades ago (Snell, 1929; Schaible and Gowen, 1961). More recently, these mutant mice were studied and found to be long-lived (Brown-Borg et al., 1996; Flurkey et al., 2001). These dwarf mice lack the hormones $\mathrm{GH}$, prolactin (PRL), and thyroid-stimulating hormone (TSH). Increasing PRL levels in these mice back to essentially normal levels by transplanting pituitary glands into them (which secrete only PRL constitutively) did not decrease their long lifespans, suggesting PRL is not involved (Flurkey et al., 2001). Treatment of Snell dwarf mice with the thyroid hormone thyroxine throughout their adulthood reduced their lifespan somewhat (Vergara et al., 2004). Hypothyroid mice have slightly increased longevity, suggesting that some but not all of the lifespan extension in dwarf mice may be due to reduced thyroid hormone levels (Ooka et al., 1983).

Interestingly, when dwarf mice were treated with GH and thyroxine for 11 weeks, they were able to grow significantly more than they normally would. Males became fertile, but they still had increased longevity, suggesting that retarded growth and reduced fertility are not the causes of increased longevity (Vergara et al., 2004). When the pituitary gland is removed in adults, lifespan is still extended, just as caloric restriction begun in adults also extends lifespan despite the fact that the animals are already fully grown (Weindruch and Walford, 1982; Powers et al., 2006). Mice expressing an antagonist of GH have reduced growth but do not live longer, further indicating that these effects can be uncoupled (Coschigano et al., 2003).

Knockout of the growth hormone receptor gene, or the growth hormone releasing hormone receptor gene, results in significantly increased longevity and reduced cancer rates (Zhou et al., 1997; Coschigano et al., 2000; Flurkey et al., 2001; Ikeno et al., 2009). Both of these mutants have extremely low levels of IGF but the former also has high levels of GH, whereas the latter has none. These results indicated that IGF itself was probably involved in regulating longevity. Heterozygous IGF-1R mutant females were shown to have increased lifespan, although the control group had elevated mortality in this study (Holzenberger et al., 2003). It has been reported that another group was unable to reproduce this increase in lifespan (unpublished data cited in Ladiges et al., 2009). Mice that overexpress IGF or GH have reduced lifespans (Steger et al., 1993; Zaina et al., 2003). However, overexpression of IGF specifically in the hearts of mice actually increased their median lifespan, although maximum lifespan was not significantly changed, and thus the aging rate itself may not have been affected (Li and Ren, 2007). IGF can also be a protective signal for heart cells (Ren et al., 1999).

When the insulin receptor was knocked out specifically in adipose tissue, these mice had increased health parameters and lived 18\% longer (Bluher et al., 2003; Katic et al., 2007). Fat itself may have negative effects on longevity as evidenced by the fact that surgical removal of fat can increase lifespan in rodents (Muzumdar et al., 2008). However, mice subjected to caloric restriction that had amounts of adipose tissue similar to those of the mice whose fat was surgically removed lived even longer (Muzumdar et al., 2008). A study in which the IRS-1, a downstream signaling component of the insulin and IGF pathways, was knocked out showed increased lifespan in mice (Selman et al., 2008). When IRS-2 was knocked out specifically in the brain of mice, they also lived longer (Taguchi et al., 2007).

In vertebrates IGF is bound and transported by a conserved family of high affinity IGF binding proteins (IGFBPs) numbered $1-6$, and virtually all IGF found in the blood is bound by IGFBPs. The IGFBPs have equal or higher affinity for IGF than the IGF-1R, so they can be inhibitory but can also act to potentiate IGF signaling in some cases (Duan and $\mathrm{Xu}, 2005)$. Some of the IGFBPs, notably IGFBP-4, a principally inhibitory binding protein, can be cleaved by a protease called "pregnancy-associated plasma protein A” (PAPP-A; Lawrence et al., 1999). Deletion of the PAPP-A gene increases mouse lifespan by around $40 \%$ and delays some effects of aging (Conover and Bale, 2007; Vallejo et al., 2009). PAPP-A may promote aging by releasing IGF from inhibitory IGFBPs (cleaved IGFBPs lose affinity for IGF), thereby increasing pro-aging IGF signaling levels (Conover, 2010).

Mutation of a gene called klotho was shown to reduce lifespan greatly, and the mutants exhibited signs of apparent accelerated aging (Kuro-O et al., 1997). Subsequently, the extracellular domain of klotho was found in the bodily fluids and shown to act as a hormone (Imura et al., 2004). Overexpression of klotho can increase the longevity of mice, suggesting more strongly that it may be involved in normal aging; it may function by suppressing insulin or IGF signaling (Kurosu et al., 2005). It has also been shown to affect other signaling pathways that may be relevant for aging (Liu et al., 2007; Wang and Sun, 2009).

Other forms of hormonal signaling have not been studied nearly as well in mice as the GH-IGF axis. Gonadal signaling has been implicated in longevity regulation. In rats, castration can increase lifespan (Drori and Folman, 1976). When the ovaries of young female mice were transplanted into older female mice whose ovaries had been removed before puberty, the lifespan of the recipients was increased by $40 \%$ relative to controls that received sham surgeries (Cargill et al., 2003). Removal of the ovaries of old mice and replacing them directly with young ovaries also extended 
lifespan of the recipients (Mason et al., 2009). Estrogen levels fall in female mammals after cessation of reproductive cycling, and this change is associated with an increased risk of CVD (Jacobsen et al., 1999). Female mice that received transplanted young ovaries after having undergone cessation of reproductive cycling were protected from the normal increase in cardiovascular risk (Mason et al., 2011). These results suggest a cell-non-autonomous effect on longevity mediated by endocrine signaling from the ovary, possibly involving estrogen, but this has yet to be determined.

In mice and most other vertebrates, the thymus, the major site of T-lymphocyte production, undergoes striking involution starting at puberty, causing it to be replaced with adipose tissue. Involution continues progressively throughout life until the organ is only a small fraction of its size at puberty, and this is thought to account for some of the reductions in immune system function that occur with age (reviewed in Taub and Longo, 2005). When old rats were castrated, the thymus regenerated, and immune functions were rejuvenated, but treatment of castrated rats with testosterone reversed these effects (Greenstein et al., 1986; Utsuyama and Hirokawa, 1989). The same effects have been found in mice and humans as well (Sutherland et al., 2005). Glucocorticoids have long been implicated in promoting thymic involution (Wyllie, 1980). It has recently been shown that testosterone signaling induces thymocytes to produce glucocorticoids, and mice that lack the glucocorticoid receptor in the thymus are completely protected from thymic involution (Chen et al., 2010). Incidentally, long-lived PAPP-A mutant mice are also protected from thymic involution (Vallejo et al., 2009).

Cell-non-autonomous effects in aging were demonstrated decades ago when it was shown that bone marrow cells from old mice were competent to repopulate bone marrow in young transplant recipients, but bone marrow cells from young individuals were not able to aid old recipients (Harrison, 1975a,b). Marrow cells can be transplanted serially and last through the lives of several generations of mice, suggesting that an intrinsic limit on cell divisions did not limit lifespan (Siminovitch et al., 1964). Adult tissue stem cells often exhibit defects in replicative capacity, or are lost altogether with age (Kuhn et al., 1996; Maslov et al., 2004; Nishimura et al., 2005; Waterstrat and Van Zant, 2009; Zhou et al., 2010). Recent studies have shown that aged muscle stem cells in old individuals could be rejuvenated by exposure to blood from young animals, suggesting that hormones in the blood regulate the aging-related changes in muscle stem cells (Conboy et al., 2005; Brack et al., 2007). FoxO3, a daf-16 homolog inhibited by the IGF pathway was shown to oppose the aging of neural stem cells (Renault et al., 2009).

\section{LESSONS FROM OTHER ANIMAL SPECIES}

In this section we discuss results of studies on the aging of three non-traditional model organisms that provide unique insights into the endocrine regulation of longevity. Some of the aging mechanisms in these organisms may not be directly relevant to humans, but understanding the diversity of regulatory mechanisms which evolution has produced is useful when considering the kinds of differences that may exist between model systems and humans (see Table 1).

\section{SOCIAL INSECTS}

Social insects like bees, ants, and termites provide interesting models for aging research because workers are typically much shorter-lived than queens giving examples of massively different lifespan being produced by the same genome. Queens in many species can live 100 times longer than their workers (Keller and Genoud, 1997). This additional longevity does not appear to be a result of increased oxidative stress resistance (Corona et al., 2005; Schneider et al., 2011). The difference in longevity between highly reproductively active queens and sterile female workers is also of interest because it suggests that investment in reproduction does not necessarily preclude "somatic maintenance" from taking place. In various mammal and bird species, it has also been found that reproductive investment is unconnected with lifespan (Ricklefs and Cadena, 2007). There have also been a number of examples from other model systems that show that fecundity and longevity can be decoupled (Gems et al., 1998; Ueyama and Fuyama, 2003; Vergara et al., 2004; Liu et al., 2005; Copeland et al., 2009; Grandison et al., 2009).

Honey bee workers begin adult life performing tasks in the hive and then transition to foraging for resources outside. Foragers have higher external mortality rates (due to predation and other hazards) but they also have more rapid declines in cognitive ability and stress resistance, and they experience exponential aging-related increases in mortality (Behrends et al., 2007; Remolina et al., 2007; Rueppell et al., 2007a,b). The lifespan of a worker is 4-8 weeks; the main determinant of lifespan is the age at which they transition to foraging (Amdam et al., 2004). This transition is promoted by $\mathrm{JH}$ signaling, and $\mathrm{JH}$ levels increase as the transition draws nearer (Jaycox et al., 1974; Fluri et al., 1982). During the winter months in temperate climates, workers become so-called "winter bees" that survive 6 months to a year; in this state their JH levels are very low (Fluri et al., 1982).

Workers are sterile and do not produce eggs but they nevertheless synthesize an evolutionarily conserved egg yolk protein called vitellogenin (Rutz and Luscher, 1974). Nurse bees use the vitellogenin to generate a secretion called royal jelly that is used to feed larvae, the queen, and other bees (Amdam et al., 2003). Young hive bees express vitellogenin at extremely high levels but expression declines with age (Fluri et al., 1982). Knockdown of vitellogenin by RNAi increases JH levels and speeds up the transition to foraging, thus reducing lifespan (Guidugli et al., 2005). Increased JH signaling also downregulated vitellogenin (Pinto et al., 2000). It has been suggested that the antagonism between these two key signals is important for regulating the transition to foraging, and thus longevity (Amdam and Omholt, 2003).

Honey bees have two ILP genes and two INR genes (Ament et al., 2008). Queens have lower IIS signaling levels than workers, and nurse bees have lower levels than foragers (Corona et al., 2007; Ament et al., 2008). This is consistent with the idea that reduced IIS extends lifespan in other organisms, but IIS also usually correlates with nutrition levels and it seems to work oppositely in honey bees (Ament et al., 2008). This unique regulatory mechanism may have evolved to maintain survival of bees with high levels of stored nutrients in order prevent loss of those resources by the colony as a whole (Munch and Amdam, 2010). 


\section{SALMON}

The Pacific Salmon of the genus Oncorhynchus are semelparous and usually die immediately after spawning. In the period leading up to sexual maturation and spawning they undergo a series of degenerative changes that resemble the effects of aging in other vertebrates. Most organs including kidney, liver, spleen, heart, and digestive tract degenerate; arteriosclerotic lesions develop in the arteries; the thymus involutes and immune functions are lost; neurodegeneration occurs, and amyloid aggregates are deposited in the brain (Robertson and Wexler, 1960; Robertson et al., 1961; Maldonado et al., 2000, 2002). Unlike most species, this senescence process in salmon is generally accepted as being evolutionarily "programmed" due to its high degree of stereotypy (Austad, 2004a).

It is believed that elevated levels of corticosteroid hormones are responsible for many of the degenerative changes in salmon (Mcquillan et al., 2003). The interrenal gland, the teleost fish homolog of the adrenal gland, undergoes hyperplasia, and corticosteroid levels become elevated fivefold or more during maturation and spawning (Hane and Robertson, 1959; Robertson and Wexler, 1960). Implantation of pellets infused with cortisol in young fish caused the same degenerative changes to occur prematurely (Robertson et al., 1963). Some Chinook salmon can mature without ever migrating out to sea, and most of these can survive a round of spawning and return to repeat the process. It was shown that the iteroparous salmon that do not die after spawning did not exhibit the same elevations in corticosteroids as semelparous members of the same species (Barry et al., 2001). When the gonad was removed from salmon before maturation, interrenal hyperplasia was prevented and lifespan was extended (Robertson, 1961). Gonadectomy prevented hypersecretion of corticosteroids, and this was rescued in gonadectomized fish by injections of androgens (Fagerlund and Donaldson, 1969). Sex steroids can directly regulate corticosteroid secretion in salmon (Mcquillan et al., 2003). Based on these results, it is believed that gonadal sex steroids regulate programmed death in salmon. It is interesting that androgen and corticosteroid signaling also seem to regulate post-mating programmed death of males in some species of dasyurid marsupials (Mcdonald et al., 1986; Mcallan, 2006).

The GH-IGF axis promotes growth and is nutritionally regulated in fish including salmon (Duan, 1998; Beckman et al., 2004), but there have so far been no studies directly linking IGF signaling to aging in salmon. However, it is interesting to note that IGF promotes synthesis of sex steroids in salmon gonads (Maestro et al., 1997) and stimulates release of gonadotropins luteinizing hormone $(\mathrm{LH})$ and follicle stimulating hormone $(\mathrm{FSH}$; Furukuma et al., 2008). In salmon, in the year before spawning, a period of rapid body growth and gonadal development takes place during which plasma IGF positively correlates with body size and Estradiol levels (Campbell et al., 2006). Increased plasma IGF levels were found in salmon with more advanced gonadal development, suggesting that IGF may be involved in linking the timing of body growth and sexual maturation in preparation for spawning (Onuma et al., 2010). The evidence is consistent with the idea that IGF signaling promotes sexual maturation and sex steroid synthesis, which in turn promotes aging-like programmed post-spawning death by inducing hypersecretion of glucocorticoids. The major lesson from these studies in salmon is that, at least in this species, endocrine signaling systems may actively promote a programmed aging process. While most other species including humans almost certainly do not undergo this sort of stereotyped programmed aging process, there may still be parallels. For instance, sex steroid-induced glucocorticoid secretion is involved in age-related thymic involution even in mammals (Chen et al., 2010).

\section{NAKED MOLE RAT}

The naked mole rat, Heterocephalus glaber, is a mammal that is approximately the same size as a mouse but lives about 10 times longer; the oldest reported naked mole rat lived 28.3 years (Buffenstein and Jarvis, 2002). Naked mole rats live in burrows and eat giant tubers that they find underground. They have a reduced threat from predators and seem to have evolved increased lifespan as a result (Buffenstein, 2005). It was thought that their extended lifespan might be due to higher resistance to oxidative stress, but it was shown that young naked mole rats actually have higher levels of oxidative damage than young mice (Andziak et al., 2006). Interestingly, naked mole rats are also extremely resistant to cancer, and tumors have never been observed in them (Seluanov et al., 2009). In naked mole rat colonies, one female and between 1 and 3 males breed, but mating is repressed in all other colony members. There is no difference in lifespan between breeders and non-breeders, and breeding continues until death (Buffenstein and Jarvis, 2002). However, in related species of mole rats, breeders have been shown to live considerably longer than non-breeders (Dammann and Burda, 2006; Dammann et al., 2011).

Information on endocrinology in naked mole rats is still limited (Edrey et al., 2011). Naked mole rats are somewhat insulin resistant and glucose intolerant (Kramer and Buffenstein, 2004). Increased insulin sensitivity has been proposed as a major mechanism of life extension. Naked mole rats have also been found to have very low thyroid hormone levels relative to other rodents (Buffenstein et al., 2001). They also show a low metabolic rate compared with mice. Since they live underground, they do not receive sunlight and are unable to synthesize vitamin D, but they are nevertheless able to regulate calcium levels (Buffenstein et al., 1994). In mice, the anti-aging hormone klotho inhibits vitamin D induced apoptosis, and klotho knockout mice have severe vitamin D toxicity (Kuro-O et al., 1997; Medici et al., 2008). Comparative studies of naked mole rats should provide insights into the endocrinology of aging in the future.

\section{HUMANS AND OTHER PRIMATES}

A number of endocrine signaling changes occur during normal aging in humans. In females one of the most significant changes is menopause, after which estrogen levels are greatly reduced (Lindsay et al., 1996). Menopause occurs at an average age of 51, and the timing of menopause (early or late) was found to be predictive of lifespan (Snowdon et al., 1989; Jacobsen et al., 1999). Hormone replacement therapy can reduce mortality rates in postmenopausal women younger than 60 (Salpeter et al., 2009). Most mammals exhibit a similar cessation of ovulation with aging, but interestingly, menstrual cycles continue basically up until death in 
our closest relative the chimpanzee (Lacreuse et al., 2008). Male testosterone levels decrease with age after puberty, and this has been termed "andropause" (Tenover, 1994; Feldman et al., 2002). Testosterone replacement therapy may have a number of beneficial effects in elderly men (reviewed in Bain, 2010). In males, the FSH and LH levels increase with advancing age (Morley et al., 1997; Feldman et al., 2002). In females, mean FSH and LH levels increase before menopause and then increase even further following menopause (Chakravarti et al., 1976; Lee et al., 1988; Lenton et al., 1988). Thyroid hormones decline in both sexes (Hesch et al., 1977; Mariotti et al., 1995). Basal levels of glucocorticoids generally do not change (Jensen and Blichert-Toft, 1971) but cortisol may increase somewhat (Van Cauter et al., 1996). Basal levels of aldosterone decrease (Flood et al., 1967). Basal levels of glucagon are unchanged in the elderly but the liver's sensitivity to it may change (Simonson and Defronzo, 1983). Growth hormone secretion (Rudman et al., 1981; Ho et al., 1987), and total serum IGF-1 levels go up during puberty and then fall with increasing age (Johanson and Blizzard, 1981; Poehlman and Copeland, 1990; Brabant et al., 2003; Veldhuis et al., 2005). About $99 \%$ of serum IGF is bound to IGFBPs, and levels of free IGF-1 decrease with age but free IGF-2 remains stable with age (Frystyk et al., 1994; Juul et al., 1997). By a different method, serum free IGF-1 was also found to increase (Janssen et al., 1998).

A number of studies have found that certain inflammatory cytokines, such as interleukin-6 (IL-6) and tumor necrosis factor alpha (TNF $\alpha)$, are elevated in healthy elderly people (Wei et al., 1992; Ershler et al., 1993; Hager et al., 1994; Ferrucci et al., 2005), but some studies have found conflicting results (Peterson et al., 1994; Beharka et al., 2001). Elevated levels of TNF $\alpha$ have been implicated in promoting the apoptosis of myocytes that leads to aging-related sarcopenia (Carbo et al., 2002; Visser et al., 2002; Pistilli et al., 2006; Schaap et al., 2009). One source of higher levels of inflammatory mediators may be adipose tissue, which increases in quantity and redistributes to different locations in older humans and mice (Morin et al., 1997; Wu et al., 2007; Kuk et al., 2009; Koster et al., 2010). Adipose tissue also secretes a number of other endocrine signaling molecules (reviewed in Galic et al., 2010), and some of these may be involved in controlling the sensitivity of tissues to the action of insulin (Xu et al., 2003; Menzaghi et al., 2007; Serrano et al., 2009; Lim et al., 2010). The prevalence of insulin resistance increases with age in humans, monkeys, and rodents (Narimiya et al., 1984; Fraze et al., 1987; Lane et al., 1995; GomezPerez et al., 2011). Insulin resistance eventually develops into type two diabetes (Groop, 1999), which also increases in prevalence with age (Cowie et al., 2006).

One of the biggest endocrine changes found in human aging is the 5- to 10-fold decrease in levels of dehydroepiandrosterone (DHEA), a steroid secreted by the adrenal glands (Orentreich et al., 1992; Ravaglia et al., 1996). Higher levels of this hormone have been linked with better health outcomes and one study has found a correlation between higher levels of DHEA and increased longevity in males (Enomoto et al., 2008). Treatment of elderly people with DHEA resulted in beneficial effects including improvement of insulin sensitivity and reduction of inflammatory cytokines (Weiss et al., 2011).
Understanding human aging is the ultimate goal of most aging research, but theories are difficult to test directly in humans. For instance, it is still unclear whether caloric restriction affects lifespan in humans, but there is evidence that even short term caloric restriction provides many of the health benefits seen in other animals, and protection from aging-related diseases such as atherosclerosis (Fontana et al., 2004; Fontana and Klein, 2007). Studies of caloric restriction in rhesus monkeys have shown reduced cancer rates, delayed immune system senescence, other beneficial health effects, and extended longevity (Mattison et al., 2003; Messaoudi et al., 2006; Colman et al., 2009). Hormonal changes in humans subjected to caloric restriction include an increase in cortisol (Fichter et al., 1986), and reductions of thyroid hormones (Roth et al., 2002; Fontana et al., 2006), leptin (Bergendahl et al., 2000; Chan et al., 2003), insulin (Fontana et al., 2004; Weiss et al., 2006), and testosterone in men (Cangemi et al., 2010). It is noteworthy that GH, IGF, and DHEA levels did not change with caloric restriction in humans (Smith, 1996; Walford et al., 2002; Heilbronn et al., 2006). However when protein intake is restricted in humans, IGF levels were decreased (Fontana et al., 2008).

There is conflicting evidence regarding IGF signaling and aging in humans. Recently a number of studies have found association between polymorphisms in genes encoding IGF pathway components and longevity. These include the IGF-1 receptor and downstream signaling components such as PI3K, AKT, and FOXO3a (Bonafe et al., 2003; Kuningas et al., 2007; Suh et al., 2008; Willcox et al., 2008; Anselmi et al., 2009; Li et al., 2009; Pawlikowska et al., 2009). A variant of the human klotho gene may also be associated with human longevity (Arking et al., 2002). In women, combinations of polymorphisms in IIS pathway genes that were expected to decrease signaling were associated with increased longevity (Van Heemst et al., 2005). In addition polymorphisms in the IGF-1R that were associated with longevity have been shown to be hypomorphic (Suh et al., 2008; Tazearslan et al., 2011). These results agree with the findings in animal models that IIS signaling and its downstream signaling pathway promote aging. Humans with mutations in the growth hormone receptor who have reduced IGF1 levels can survive to old age (Laron, 2005). However, humans with hypopituitarism and deficiencies in growth hormone who are not treated with growth hormone have reduced lifespan (Besson et al., 2003). Patients with acromegaly (excessive growth hormone and IGF-1 levels) also have reduced lifespan, especially when untreated (Bates et al., 1993).

A large number of studies over the last decade have looked for associations between serum IGF-1 levels in humans and risk of dying from all-causes over a subsequent follow-up period. Some of these have found no association between serum IGF-1 levels and risk of all-cause mortality (Laughlin et al., 2004; Saydah et al., 2007; Kaplan et al., 2008; Hu et al., 2009; Yeap et al., 2011). However, some studies did find that lower levels of serum IGF-1 (Cappola et al., 2003; Roubenoff et al., 2003; Friedrich et al., 2009), or serum IGF bioactivity (Brugts et al., 2008), were associated with greater all-cause mortality risk. At least one study also found that higher IGF-1 levels were associated with greater all-cause mortality risk (Andreassen et al., 2009), and two studies found greater risk for subjects with both low and high levels (Van Bunderen et al., 2010; Friedrich et al., 2011). Based on these results, it is still unclear 
whether infusions of IGF would be beneficial or detrimental in older people.

\section{ATHEROSCLEROSIS AND CARDIOVASCULAR DISEASE}

Cardiovascular disease, which includes heart attack, stroke, and heart failure is by far the most common aging-related cause of death in elderly humans (Xu et al., 2010). Incidences of CVD increase exponentially with age (Driver et al., 2008). The underlying cause of most CVD is atherosclerosis, a disease of the arteries in which complex lipid-containing inflammatory lesions called atheromatous plaques form beneath the endothelial cell lining. Treatments (drugs and diets) that reduce plasma low density lipoprotein (LDL) levels protect against atherosclerosis in humans (Gould et al., 1998) even in people who already have extremely low LDL levels (Leeper et al., 2007). Atherosclerosis does not occur in rodents unless they are fed an "atherogenic" high fat, high cholesterol diet (Armstrong and Heistad, 1990), and animals normally have much lower LDL levels than the average for humans (Mills and Taylaur, 1971). Mice are particularly resistant to atherosclerosis, but apolipoprotein E (ApoE) and LDL receptor (LDLR) knockout mice, which have massively elevated LDL levels, do develop atherosclerosis early in life (Plump et al., 1992; Zhang et al., 1992; Ishibashi et al., 1994). Humans who are deficient in the LDL receptor, which removes LDL from the blood, are also extremely prone to atherosclerosis at an early age (Mabuchi et al., 1986). LDL particles are actively transported through the endothelial cell layer to the subendothelial matrix (Vasile et al., 1983; Ishibashi et al., 1994) where they bind to negatively charged proteoglycan molecules, and accumulate (Skalen et al., 2002; Tabas et al., 2007; Nakashima et al., 2008). The aggregated LDL particles eventually provoke a complex inflammatory response involving recruitment of immune cells, leading to further plaque development (reviewed in Galkina and Ley, 2009).

The arteries change with age and become more susceptible to atherosclerosis (reviewed in Lakatta et al., 2009). The changes include a thickening and stiffening of the extracellular matrixrich inner layer of the artery wall (the intima) and an increase in the number of vascular smooth muscle cells in this zone (Virmani et al., 1991; Orlandi et al., 1993; Nagai et al., 1998; Li et al., 1999; Wang et al., 2003, 2007a). Atherosclerosis preferentially occurs at sites of thickened intima (Orlandi et al., 2000; Nakashima et al., 2007). In mice, rabbits, and monkeys, when young and old animals were fed atherogenic diets, the older animals developed more advanced and more severe atherosclerosis than the younger ones in the same time period (Clarkson et al., 1969; Spagnoli et al., 1991; Orlandi et al., 2000; Collins et al., 2009). The progression of atherosclerosis in humans is accelerated in the premature aging diseases, Werner syndrome and Hutchinson-Gilford Progeria, despite a lack of elevated LDL or other risk factors (Cohen et al., 1987; Gordon et al., 2005; Hennekam, 2006; Cao et al., 2007; Olive et al., 2010) and in a mouse model of premature aging (Fenton et al., 2004).

Insulin-like growth factor 1 signaling seems to be involved in regulating the rate of the underlying aging process, and this may promote the arterial remodeling that increases susceptibility to atherosclerosis. In recent years, some association studies have found that higher levels of IGF- 1 are associated with increased risk of CVD (Fischer et al., 2004; Kawachi et al., 2005; Schneider et al., 2008; Andreassen et al., 2009). However, some studies have shown the opposite result, that lower levels of IGF-1 predict higher risk of CVD (Juul et al., 2002; Vasan et al., 2003; Laughlin et al., 2004; Johnsen et al., 2005; Friedrich et al., 2009). Some studies also found no association between IGF-1 levels and CVD (Saydah et al., 2007; Yeap et al., 2011); one found that both high and low levels showed increased risk of CVD (Van Bunderen et al., 2010). Humans with a genetic polymorphism in the promoter of the IGF-1 gene that resulted in an average of $18 \%$ less IGF-1 in their serum were found to be at higher risk for heart attack (Vaessen et al., 2001). Hypopituitarism and acromegaly, which cause a deficiency or excess, respectively, in activity of the GH-IGF-1 axis, both cause increased risk of CVD (Rosen and Bengtsson, 1990; Clayton, 2003).

The role of IGF in atherosclerosis has been extensively studied. ApoE knockout mice that were engineered to have a genetic polymorphism that results in $20 \%$ less circulating IGF-1 had an increased atherosclerotic plaque burden compared with control ApoE knockout mice (Shai et al., 2011). Infusion of recombinant IGF-1 into the blood of ApoE knockout mice resulted in decreased plaque burden (Sukhanov et al., 2007). However, overexpression of IGF-1 in VSMCs in ApoE knockout mice did not reduce the plaque burden but the plaques showed signs of increased stability (Shai et al., 2010). Overexpression of IGF-1 in smooth muscle tissue does cause VSMC proliferation and hyperplasia (Wang et al., 1997). PAPP-A, which increases IGF bioavailability by cleaving inhibitory IGFBPs, is enriched in atherosclerotic plaques, and in the blood in people with coronary artery disease and unstable atherosclerotic plaques (Bayes-Genis et al., 2001a; Beaudeux et al., 2003; Lund et al., 2003; Heider et al., 2010). Knockout of PAPP-A in mice extends lifespan, as mentioned previously, and also delays aging-related pathology, including reduced degenerative cardiovascular changes (Conover et al., 2010a). Knockout of PAPP-A in ApoE knockout mice reduced the size of their atherosclerotic lesions (Harrington et al., 2007), and overexpression of PAPP-A in ApoE knockout mice increased lesion size (Conover et al., 2010b). Overexpression of a protease-resistant form of IGFBP-4, a major PAPP-A target (Parker et al., 1995; Bayes-Genis et al., 2001b), inhibits smooth muscle cell growth in mice (Zhang et al., 2002). Infusion of the protease-resistant form of IGFBP-4 into hypercholesterolemic pigs reduced the size of their atherosclerotic lesions, and this effect was prevented by simultaneous infusion of IGF-1 (Nichols et al., 2007). ApoE knockout mice that also lack IGF-2 have reduced atherosclerotic lesion size compared with control ApoE knockout mice, suggesting that IGF-2 promotes atherosclerosis (Zaina et al., 2002). Constitutive IGF1R tyrosine kinase activity was found in VSMCs from old rats but not young rats (Li et al., 2008). It has been suggested that IGF-1 in the blood protects against plaque rupture by inhibiting VSMC apoptosis (Conti et al., 2011). Based on the evidence discussed above, it seems likely that IGF signaling, especially by IGF-2, also plays a role in promoting atherosclerosis, perhaps at the level of paracrine signaling within the arterial intima. IGF also protects the heart by inhibiting cardiomyocyte apoptosis (Lee et al., 1999), which normally causes an aging-related decline in heart function even in the absence of disease (Olivetti et al., 1997). 
There is evidence to suggest that signaling by the hormone angiotensin II plays a role in promoting aging-related changes in the arteries. Angiotensin II is the final and most active product of the renin-angiotensin system whose primary role is to regulate blood pressure (Mehta and Griendling, 2007). Angiotensin II induces vasoconstriction by binding to and activating angiotensin type 1 receptors (AT1) on vascular smooth muscle cells. Angiotensin signaling might play a role in aging. Knockout of the major isoform of AT1 in mice (AT1a) increases lifespan (Benigni et al., 2009). Long-term treatment of rats with inhibitors that reduce angiotensin signaling protected against aging-related changes in the cardiovascular system and also extended their lifespans (Basso et al., 2007). Double knockout mice lacking both AT1a and ApoE had significantly smaller atherosclerotic lesions at 60 weeks of age than mice lacking only ApoE, indicating that AT1 signaling promotes atherosclerosis progression (Eto et al., 2008). The arterial walls of aged mice and non-human primates contain higher levels of angiotensin-converting enzyme (ACE), angiotensin II, and other components of the angiotensin signaling pathway (Wang et al., 2003, 2007a). Treatment of young rats with angiotensin II causes changes in their artery walls that reproduce changes that normally occur with aging (Wang et al., 2005). Angiotensin II increases expression of the IGF-1R in VSMCs, and this may be involved in the mechanism by which angiotensin II promotes VSMC proliferation (Du et al., 1999).

\section{CANCER}

The second most common cause of death in the elderly is cancer (Xu et al., 2010). Rates of cancer incidence increase with age but actually fall after the ninth decade (Driver et al., 2008). Cancer seems to be linked to the rate of the underlying aging process, in that processes like speciation and selective breeding that can alter lifespan also affect the rate of cancer incidence (Miller, 1991). Caloric restriction reduces cancer rates in mice and non-human primates (Weindruch and Walford, 1982; Weindruch et al., 1986; Colman et al., 2009). C. elegans mutants with extended longevity, including IIS mutants, have reduced growth of germ line tumors (Pinkston et al., 2006; Pinkston-Gosse and Kenyon, 2007). Dwarf mice, GH receptor knockout mice, and PAPP-A knockout mice have reduced and/or delayed cancer occurrence (Ikeno et al., 2003, 2009; Conover et al., 2010a). Humans with a variety of mutations that confer congenital IGF-1 deficiency are protected from cancer (Shevah and Laron, 2007). A number of association studies have found that higher serum IGF levels correlate with higher risk for specific cancers (Chan et al., 1998; Hankinson et al., 1998; Ma et al., 1999; Yu et al., 1999; Probst-Hensch et al., 2001; Renehan et al., 2004; Gunter et al., 2009), and general cancer mortality in elderly men (Major et al., 2010). IGFs promote growth, proliferation, and protection against apoptosis, and are directly involved in promoting tumorigenesis (reviewed in Pollak, 2008). High levels of insulin may also increase the risk of cancer in humans (Pisani, 2008). Reductions in IIS signaling seem to protect against cancer but a major question is whether this is caused by a delay in the aging process or simply an inhibition of tumor growth due to the reduced availability of an important growth factor. The fact that $\mathrm{GH}$ deficient mice are resistant to chemical carcinogenesis suggests that a reduction in the GH-IGF-1 axis may actually increase resistance to DNA mutation (Ramsey et al., 2002). FOXO transcription factors, which are inhibited by IIS signaling, have been shown to act as tumor suppressors (Paik et al., 2007), and FoxO3a has been shown to activate DNA repair (Tran et al., 2002). After a tumor has already formed, many endocrine signaling systems can be co-opted by the cancer cells to promote their own proliferation; an account of all of these is beyond the scope of this review.

\section{THE NEED FOR NEW MODEL SYSTEMS}

In the last two decades, genetic studies using very short-lived model organisms including flies, worms, and yeast (which have not been discussed here due to their lack of "endocrine" signaling) have revealed a wealth of new knowledge about the molecular basis of aging. The advantage of short-lived models is that they are amenable to "lifespan extension experiments," that is, experiments in which a genetic manipulation or intervention is tested with the hypothesis that it will extend the lifespan. An extension of maximum lifespan, coupled with a retardation of demographic senescence, and a delay in aging-related disease incidence, is one of the most robust ways to demonstrate the involvement of the manipulated process or mechanism in normal aging. Conversely, when only reductions in levels of markers associated with aging, or a reduction in lifespan is reported, it is difficult to know whether these effects are truly due to changes in aging rate.

Short-lived models also have the disadvantage that it is impossible to know whether any given mechanism that is demonstrated to be at work in a short-lived organism is also present in longerlived organisms such as humans. Many short-lived organisms are distant from humans on the tree of life and differ in certain aspects of their biology. One way to address this problem is to study each process in multiple different short-lived organisms from different phyla and confirm broad evolutionary conservation. C. elegans and Drosophila alone may be insufficient for this due to their phyla belonging to the same superphylum of ecdysozoa (Mallatt and Winchell, 2002; Dunn et al., 2008). Another approach would be to study long-lived organisms and focus on the differences between young and old individuals. This may be necessary in order to uncover ways to extend the lifespan of already long-lived humans.

It is clear that new model systems will be a useful addition to aging research (see Table 1). The honey bee as a social insect and the naked mole rat as a relatively long-lived mammal as discussed above are now being studied more extensively (Buffenstein, 2005; Munch and Amdam, 2010). In addition, extremely long-lived mollusks (bivalves) that live hundreds of years are beginning to be studied (Philipp and Abele, 2010). Some fish can also live more than 200 years and continue reproduction into advanced age (De Bruin et al., 2004; Mangel et al., 2007). Zebrafish are now being studied as a gradually aging fish model system (Gerhard et al., 2002). Zebrafish can live up to $4-5$ years and thus, despite their many advantages (small size, genetic tractability, etc.), they cannot be used for the same kinds of rapid aging experiments as Drosophila and C. elegans.

Another fish model that is gaining traction is the exceptionally short-lived annual killifish Nothobranchius furzeri. N. furzeri 
has the advantages of being both short-lived, with a maximum lifespan of around 3 months in the shortest-lived strain (Valdesalici and Cellerino, 2003; Terzibasi et al., 2008), and being a vertebrate and therefore sharing many biological features with humans that are not shared by lower organisms (Valdesalici and Cellerino, 2003; Austad, 2004b). An initial characterization of the N. furzeri genome has been published (Reichwald et al., 2009), and a number of vertebrate aging genes have been cloned (Genade et al., 2005). The appearance of aging-related biomarkers and aging pathology have been characterized, and they suggest that the aging process in $N$. furzeri follows a normal pattern but is highly accelerated (Genade et al., 2005; Di Cicco et al., 2011).

\section{CONCLUDING REMARKS}

Our current understanding of the endocrinology of aging is still incomplete and many open questions exist. Mutants that are deficient in a particular endocrine signaling pathway throughout life have provided most of the evidence that endocrine signaling is involved in regulating aging. It is generally unknown whether hormones actively influence the rate of the aging process or are simply required during a certain period to stimulate a developmental progression that later influences aging. Another major open question is, to what extent will the findings on the endocrine regulation of aging in model organisms be applicable to humans, and will hormone replacement or modulation therapies be effective

\section{REFERENCES}

Alcedo, J., and Kenyon, C. (2004). Regulation of C. elegans longevity by specific gustatory and olfactory neurons. Neuron 41, 45-55.

Altaratz, M., Applebaum, S. W., Richard, D. S., Gilbert, L. I., and Segal, D. (1991). Regulation of juvenile hormone synthesis in wild-type and apterous mutant Drosophila. Mol. Cell. Endocrinol. 81, 205-216.

Amdam, G. V., Norberg, K., Hagen, A., and Omholt, S. W. (2003). Social exploitation of vitellogenin. Proc. Natl. Acad. Sci. U.S.A. 100, 1799-1802.

Amdam, G. V., and Omholt, S. W. (2003). The hive bee to forager transition in honeybee colonies: the double repressor hypothesis. J. Theor. Biol. 223, 451-464.

Amdam, G. V., Simoes, Z. L., Hagen, A., Norberg, K., Schroder, K., Mikkelsen, O., Kirkwood, T. B., and Omholt, S. W. (2004). Hormonal control of the yolk precursor vitellogenin regulates immune function and longevity in honeybees. Exp. Gerontol. 39, 767-773.

Ament, S. A., Corona, M., Pollock, H. S., and Robinson, G. E. (2008). Insulin signaling is involved in the regulation of worker division of labor in honey bee colonies. Proc. Natl. Acad. Sci. U.S.A. 105, 4226-4231.

Andreassen, M., Raymond, I., Kistorp, C., Hildebrandt, P., Faber, J., and Kristensen, L. O. (2009). IGF1 as

in treating or delaying aging-related diseases? Further research should increase our understanding of the endocrine pathways that regulate aging and the molecular mechanisms by which hormones affect the aging rate in different species.

A major lesson from studies in comparative endocrinology is that IIS signaling is involved in regulating longevity in many different species. This is logical considering its role as a highly conserved pathway that promotes growth and is regulated by nutritional status. IIS genes are good candidates for antagonistically pleiotropic genes because IIS signaling usually promotes fecundity in addition to aging. However, in many cases, aging and fecundity have been shown to be decoupled, indicating that a simple trade-off between reproduction and longevity is not necessarily sufficient to explain the causes of aging. Caloric restriction promotes longevity in virtually all species that have been examined and IIS signaling is likely at least partially involved in this phenomenon in some species. Further studies on the comparative endocrinology of aging may provide more evidence to link steroids and other hormones more concretely to longevity regulation in mammals.

\section{ACKNOWLEDGMENTS}

We acknowledge the many investigators who have made contributions to the understanding of endocrinology of aging whose work we were unable to cite due to space constraints. Research in the Duan lab is supported by NSF Research Grant IOS-1051034.

Mcintosh, I., and Dietz, H. C. (2002). Association of human aging with a functional variant of klotho. Proc. Natl. Acad. Sci. U.S.A. 99, 856-861.

Armstrong, M. L., and Heistad, D. D. (1990). Animal models of atherosclerosis. Atherosclerosis 85, 15-23.

Austad, S. N. (1989). Life extension by dietary restriction in the bowl and doily spider, Frontinella pyramitela. Exp. Gerontol. 24, 83-92.

Austad, S. N. (2004a). Is aging programed? Aging Cell 3, 249-251.

Austad, S. N. (2004b). On Herrera and Jagadeeswaran's “annual fish as a genetic model for aging." $J$. Gerontol. A Biol. Sci. Med. Sci. 59, 99-100.

Ayyadevara, S., Alla, R., Thaden, J. J., and Shmookler Reis, R. J. (2008). Remarkable longevity and stress resistance of nematode PI3K-null mutants. Aging Cell 7, 13-22.

Bain, J. (2010). Testosterone and the aging male: to treat or not to treat? Maturitas 66, 16-22.

Barry, T. P., Unwin, M. J., Malison, J. A., and Quinn, T. P. (2001). Free and total cortisol levels in semelparous and iteroparous chinook salmon. J. Fish Biol. 59, 1673-1676.

Bartke, A., Wright, J. C., Mattison, J. A., Ingram, D. K., Miller, R. A., and Roth, G. S. (2001). Extending the lifespan of long-lived mice. Nature 414, 412.

Basso, N., Cini, R., Pietrelli, A., Ferder, L., Terragno, N. A., and Inserra,
F. (2007). Protective effect of longterm angiotensin II inhibition. Am. J. Physiol. Heart Circ. Physiol. 293, H1351-H1358.

Bates, A. S., Van't Hoff, W., Jones, J. M., and Clayton, R. N. (1993) An audit of outcome of treatment in acromegaly. Q. J. Med. 86, 293-299.

Bayes-Genis, A., Conover, C. A., Overgaard, M. T., Bailey, K. R., Christiansen, M., Holmes, D. R. Jr., Virmani, R., Oxvig, C., and Schwartz, R. S. (2001a). Pregnancy-associated plasma protein $\mathrm{A}$ as a marker of acute coronary syndromes. N. Engl. J. Med. 345, 1022-1029.

Bayes-Genis, A., Schwartz, R. S., Lewis, D. A., Overgaard, M. T., Christiansen, M., Oxvig, C., Ashai, K., Holmes, D. R. Jr., and Conover, C. A. (2001b). Insulin-like growth factor binding protein-4 protease produced by smooth muscle cells increases in the coronary artery after angioplasty. Arterioscler. Thromb. Vasc. Biol. 21, 335-341.

Beaudeux, J. L., Burc, L., ImbertBismut, F., Giral, P., Bernard, M., Bruckert, E., and Chapman, M. J. (2003). Serum plasma pregnancy-associated protein A: a potential marker of echogenic carotid atherosclerotic plaques in asymptomatic hyperlipidemic subjects at high cardiovascular risk. Arterioscler. Thromb. Vasc. Biol. 23, e7-e10. 
Beckman, B. R., Shimizu, M., Gadberry, B. A., and Cooper, K. A. (2004). Response of the somatotropic axis of juvenile coho salmon to alterations in plane of nutrition with an analysis of the relationships among growth rate and circulating IGF-I and 41 kDa IGFBP. Gen. Comp. Endocrinol. 135, 334-344.

Beharka, A. A., Meydani, M., Wu, D., Leka, L. S., Meydani, A., and Meydani, S. N. (2001). Interleukin-6 production does not increase with age. J. Gerontol. A Biol. Sci. Med. Sci. 56, B81-B88.

Behrends, A., Scheiner, R., Baker, N., and Amdam, G. V. (2007). Cognitive aging is linked to social role in honey bees (Apis mellifera). Exp. Gerontol. 42, 1146-1153.

Benigni, A., Corna, D., Zoja, C., Sonzogni, A., Latini, R., Salio, M., Conti, S., Rottoli, D., Longaretti, L., Cassis, P., Morigi, M., Coffman, T. M., and Remuzzi, G. (2009). Disruption of the Ang II type 1 receptor promotes longevity in mice. J. Clin. Invest. 119, 524-530.

Bergendahl, M., Iranmanesh, A., Evans, W. S., and Veldhuis, J. D. (2000). Short-term fasting selectively suppresses leptin pulse mass and 24hour rhythmic leptin release in healthy midluteal phase women without disturbing leptin pulse frequency or its entropy control (pattern orderliness). J. Clin. Endocrinol. Metab. 85, 207-213.

Berman, J. R., and Kenyon, C. (2006). Germ-cell loss extends C. elegans life span through regulation of DAF16 by kri-1 and lipophilic-hormone signaling. Cell 124, 1055-1068.

Besson, A., Salemi, S., Gallati, S., Jenal, A., Horn, R., Mullis, P. S., and Mullis, P. E. (2003). Reduced longevity in untreated patients with isolated growth hormone deficiency. J. Clin. Endocrinol. Metab. 88, 3664-3667.

Bishop, N. A., and Guarente, L. (2007). Two neurons mediate dietrestriction-induced longevity in $C$. elegans. Nature 447, 545-549.

Black, B. J. Jr., Mcmahan, C. A., Masoro, E. J., Ikeno, Y., and Katz, M. S. (2003). Senescent terminal weight loss in the male F344 rat. Am. J. Physiol. Regul. Integr. Comp. Physiol. 284, R336-R342.

Bluher, M., Kahn, B. B., and Kahn, C. R. (2003). Extended longevity in mice lacking the insulin receptor in adipose tissue. Science 299, 572-574.

Bonafe, M., Barbieri, M., Marchegiani, F., Olivieri, F., Ragno, E., Giampieri, C., Mugianesi, E., Centurelli, M., Franceschi, C., and Paolisso, G. (2003). Polymorphic variants of insulin-like growth factor I (IGFI) receptor and phosphoinositide 3-kinase genes affect IGF-I plasma levels and human longevity: cues for an evolutionarily conserved mechanism of life span control. J. Clin. Endocrinol. Metab. 88, 3299-3304.

Bonkowski, M. S., Dominici, F. P., Arum, O., Rocha, J. S., Al Regaiey, K. A., Westbrook, R., Spong, A., Panici, J., Masternak, M. M., Kopchick, J. J., and Bartke, A. (2009). Disruption of growth hormone receptor prevents calorie restriction from improving insulin action and longevity. PLoS ONE 4, e4567. doi:10.1371/journal.pone.0004567

Brabant, G., Von Zur Muhlen, A., Wuster, C., Ranke, M. B., Kratzsch, J., Kiess, W., Ketelslegers, J. M., Wilhelmsen, L., Hulthen, L., Saller, B., Mattsson, A., Wilde, J., Schemer, R., and Kann, P. (2003). Serum insulinlike growth factor I reference values for an automated chemiluminescence immunoassay system: results from a multicenter study. Horm. Res. 60, 53-60.

Brack, A. S., Conboy, M. J., Roy, S., Lee, M., Kuo, C. J., Keller, C., and Rando, T. A. (2007). Increased Wnt signaling during aging alters muscle stem cell fate and increases fibrosis. Science 317, 807-810.

Breese, C. R., Ingram, R. L., and Sonntag, W. E. (1991). Influence of age and long-term dietary restriction on plasma insulin-like growth factor-1 (IGF-1), IGF-1 gene expression, and IGF-1 binding proteins. J. Gerontol. 46, B180-B187.

Brogiolo, W., Stocker, H., Ikeya, T., Rintelen, F., Fernandez, R., and Hafen, E. (2001). An evolutionarily conserved function of the Drosophila insulin receptor and insulin-like peptides in growth control. Curr. Biol. 11, 213-221.

Broue, F., Liere, P., Kenyon, C., and Baulieu, E. E. (2007). A steroid hormone that extends the lifespan of Caenorhabditis elegans. Aging Cell 6, 87-94.

Broughton, S. J., Piper, M. D., Ikeya, T., Bass, T. M., Jacobson, J., Driege, Y., Martinez, P., Hafen, E., Withers, D. J., Leevers, S. J., and Partridge, L. (2005). Longer lifespan, altered metabolism, and stress resistance in Drosophila from ablation of cells making insulin-like ligands. Proc. Natl. Acad. Sci. U.S.A. 102, 3105-3110.

Broughton, S. J., Slack, C., Alic, N., Metaxakis, A., Bass, T. M., Driege, Y., and Partridge, L. (2010). DILPproducing median neurosecretory cells in the Drosophila brain mediate the response of lifespan to nutrition. Aging Cell 9, 336-346.

Brown-Borg, H. M., Borg, K. E., Meliska, C. J., and Bartke, A. (1996). Dwarf mice and the ageing process. Nature 384, 33.

Brugts, M. P., Van Den Beld, A. W., Hofland, L. J., Van Der Wansem, K., Van Koetsveld, P. M., Frystyk, J., Lamberts, S. W., and Janssen, J. A. (2008). Low circulating insulin-like growth factor I bioactivity in elderly men is associated with increased mortality. J. Clin. Endocrinol. Metab. 93, 2515-2522.

Buffenstein, R. (2005). The naked molerat: a new long-living model for human aging research. J. Gerontol. A Biol. Sci. Med. Sci. 60, 1369-1377.

Buffenstein, R., and Jarvis, J. U. (2002). The naked mole rat-a new record for the oldest living rodent. Sci. Aging Knowledge Environ. 2002, pe7.

Buffenstein, R., Jarvis, J. U., Opperman, L. A., Cavaleros, M., Ross, F. P., and Pettifor, J. M. (1994). Subterranean mole-rats naturally have an impoverished calciol status, yet synthesize calciol metabolites and calbindins. Eur. J. Endocrinol. 130, 402-409.

Buffenstein, R., Woodley, R., Thomadakis, C., Daly, T. J., and Gray, D. A. (2001). Cold-induced changes in thyroid function in a poikilothermic mammal, the naked mole-rat. Am. J. Physiol. Regul. Integr. Comp. Physiol. 280, R149-R155.

Campbell, B., Dickey, J., Beckman, B., Young, G., Pierce, A., Fukada, H., and Swanson, P. (2006). Previtellogenic oocyte growth in salmon: relationships among body growth, plasma insulin-like growth factor-1, estradiol-17beta, follicle-stimulating hormone and expression of ovarian genes for insulin-like growth factors, steroidogenic-acute regulatory protein and receptors for gonadotropins, growth hormone, and somatolactin. Biol. Reprod. 75, 34-44.

Cangemi, R., Friedmann, A. J., Holloszy, J. O., and Fontana, L. (2010). Longterm effects of calorie restriction on serum sex-hormone concentrations in men. Aging Cell 9, 236-242.

Cao, K., Capell, B. C., Erdos, M. R., Djabali, K., and Collins, F. S. (2007). A lamin A protein isoform overexpressed in HutchinsonGilford progeria syndrome interferes with mitosis in progeria and normal cells. Proc. Natl. Acad. Sci. U.S.A. 104, 4949-4954.

Cappola, A. R., Xue, Q. L., Ferrucci, L., Guralnik, J. M., Volpato, S., and Fried, L. P. (2003). Insulin-like growth factor I and interleukin-6 contribute synergistically to disability and mortality in older women. J. Clin. Endocrinol. Metab. 88, 2019-2025.
Carbo, N., Busquets, S., Van Royen, M., Alvarez, B., Lopez-Soriano, F. J., and Argiles, J. M. (2002). TNF-alpha is involved in activating DNA fragmentation in skeletal muscle. Br. J. Cancer 86, 1012-1016.

Cargill, S. L., Carey, J. R., Muller, H. G., and Anderson, G. (2003). Age of ovary determines remaining life expectancy in old ovariectomized mice. Aging Cell 2, 185-190.

Cassada, R. C., and Russell, R. L. (1975). The dauerlarva, a post-embryonic developmental variant of the nematode Caenorhabditis elegans. Dev. Biol. 46, 326-342.

Chakravarti, S., Collins, W. P., Forecast, J. D., Newton, J. R., Oram, D. H., and Studd, J. W. (1976). Hormonal profiles after the menopause. $\mathrm{Br}$. Med. J. 2, 784-787.

Chan, J. L., Heist, K., Depaoli, A. M., Veldhuis, J. D., and Mantzoros, C. S. (2003). The role of falling leptin levels in the neuroendocrine and metabolic adaptation to short-term starvation in healthy men. J. Clin. Invest. 111, 1409-1421.

Chan, J. M., Stampfer, M. J., Giovannucci, E., Gann, P. H., Ma, J., Wilkinson, P., Hennekens, C. H., and Pollak, M. (1998). Plasma insulin-like growth factor-I and prostate cancer risk: a prospective study. Science 279 , 563-566.

Chapman, T., and Partridge, L. (1996). Female fitness in Drosophila melanogaster: an interaction between the effect of nutrition and of encounter rate with males. Proc. Biol. Sci. 263, 755-759.

Chen, Y., Qiao, S., Tuckermann, J., Okret, S., and Jondal, M. (2010) Thymus-derived glucocorticoids mediate androgen effects on thymocyte homeostasis. FASEB J. 24, 5043-5051.

Cheney, K. E., Liu, R. K., Smith, G. S., Leung, R. E., Mickey, M. R., and Walford, R. L. (1980). Survival and disease patterns in $\mathrm{C} 57 \mathrm{BL} / 6 \mathrm{~J}$ mice subjected to undernutrition. Exp. Gerontol. 15, 237-258.

Clancy, D. J., Gems, D., Hafen, E., Leevers, S. J., and Partridge, L. (2002). Dietary restriction in longlived dwarf flies. Science 296, 319.

Clancy, D. J., Gems, D., Harshman, L. G., Oldham, S., Stocker, H., Hafen, E., Leevers, S. J., and Partridge, L. (2001). Extension of life-span by loss of CHICO, a Drosophila insulin receptor substrate protein. Science 292, 104-106.

Clarkson, T. B., Lofland, H. B., Bullock, B. C., Lehner, N. D., St Clair, R., and Prichard, R. W. (1969). Atherosclerosis in some species of New World monkeys. Ann. N. Y. Acad. Sci. 162, 103-109. 
Clayton, R. N. (2003). Cardiovascular function in acromegaly. Endocr. Rev. 24, 272-277.

Cohen, J. I., Arnett, E. N., Kolodny, A. L., and Roberts, W. C. (1987). Cardiovascular features of the Werner syndrome. Am. J. Cardiol. 59, 493-495.

Collins, A. R., Lyon, C. J., Xia, X., Liu, J. Z., Tangirala, R. K., Yin, F., Boyadjian, R., Bikineyeva, A., Pratico, D., Harrison, D. G., and Hsueh, W. A. (2009). Age-accelerated atherosclerosis correlates with failure to upregulate antioxidant genes. Circ. Res. 104, e42-e54.

Colman, R. J., Anderson, R. M., Johnson, S. C., Kastman, E. K., Kosmatka, K. J., Beasley, T. M., Allison, D. B., Cruzen, C., Simmons, H. A., Kemnitz, J. W., and Weindruch, R. (2009). Caloric restriction delays disease onset and mortality in rhesus monkeys. Science 325, 201-204.

Colman, R. J., Beasley, T. M., Allison, D. B., and Weindruch, R. (2008). Attenuation of sarcopenia by dietary restriction in rhesus monkeys. J. Gerontol. A Biol. Sci. Med. Sci. 63, 556-559.

Colombani, J., Bianchini, L., Layalle, S., Pondeville, E., Dauphin-Villemant, C., Antoniewski, C., Carre, C., Noselli, S., and Leopold, P. (2005). Antagonistic actions of ecdysone and insulins determine final size in Drosophila. Science 310, 667-670.

Comfort, A. (1963). Effect of delayed and resumed growth on the longevity of a fish (Lebistes reticulatus, Peters) in captivity. Gerontologia 49, 150-155.

Conboy, I. M., Conboy, M. J., Wagers, A. J., Girma, E. R., Weissman, I. L., and Rando, T. A. (2005). Rejuvenation of aged progenitor cells by exposure to a young systemic environment. Nature 433, 760-764.

Conover, C. A. (2010). PAPP-A: a new anti-aging target? Aging Cell 9, 942-946.

Conover, C. A., and Bale, L. K. (2007). Loss of pregnancy-associated plasma protein A extends lifespan in mice. Aging Cell 6, 727-729.

Conover, C. A., Bale, L. K., Mader, J. R., Mason, M. A., Keenan, K. P., and Marler, R. J. (2010a). Longevity and age-related pathology of mice deficient in pregnancy-associated plasma protein-A. J. Gerontol. A Biol. Sci. Med. Sci. 65, 590-599.

Conover, C. A., Mason, M. A., Bale, L. K., Harrington, S. C., Nyegaard, M., Oxvig, C., and Overgaard, M. T. (2010b). Transgenic overexpression of pregnancy-associated plasma protein-A in murine arterial smooth muscle accelerates atherosclerotic lesion development. Am. J. Physiol. Heart Circ. Physiol. 299, H284-H291.
Conti, E., Musumeci, M. B., De Giusti, M., Dito, E., Mastromarino, V., Autore, C., and Volpe, M. (2011). IGF-1 and atherothrombosis: relevance to pathophysiology and therapy. Clin. Sci. 120, 377-402.

Copeland, J. M., Cho, J., Lo, T. Jr., Hur, J. H., Bahadorani, S., Arabyan, T., Rabie, J., Soh, J., and Walker, D. W. (2009). Extension of Drosophila life span by RNAi of the mitochondrial respiratory chain. Curr. Biol. 19, 1591-1598.

Corona, M., Hughes, K. A., Weaver, D. B., and Robinson, G. E. (2005). Gene expression patterns associated with queen honey bee longevity. Mech. Ageing Dev. 126, 1230-1238.

Corona, M., Velarde, R. A., Remolina, S., Moran-Lauter, A., Wang, Y., Hughes, K. A., and Robinson, G. E. (2007). Vitellogenin, juvenile hormone, insulin signaling, and queen honey bee longevity. Proc. Natl. Acad. Sci. U.S.A. 104, 7128-7133.

Coschigano, K. T., Clemmons, D., Bellush, L. L., and Kopchick, J. J. (2000). Assessment of growth parameters and life span of GHR/BP genedisrupted mice. Endocrinology 141, 2608-2613.

Coschigano, K. T., Holland, A. N., Riders, M. E., List, E. O., Flyvbjerg, A., and Kopchick, J. J. (2003). Deletion, but not antagonism, of the mouse growth hormone receptor results in severely decreased body weights, insulin, and insulin-like growth factor I levels and increased life span. Endocrinology 144, 3799-3810.

Cowie, C. C., Rust, K. F., Byrd-Holt, D. D., Eberhardt, M. S., Flegal, K. M., Engelgau, M. M., Saydah, S. H., Williams, D. E., Geiss, L. S., and Gregg, E. W. (2006). Prevalence of diabetes and impaired fasting glucose in adults in the U.S. population: National Health and Nutrition Examination Survey 1999-2002. Diabetes Care 29, 1263-1268.

Dammann, P., and Burda, H. (2006). Sexual activity and reproduction delay ageing in a mammal. Curr. Biol. 16, R117-R118.

Dammann, P., Sumbera, R., Massmann, C., Scherag, A., and Burda, H. (2011). Extended longevity of reproductives appears to be common in Fukomys mole-rats (Rodentia, Bathyergidae). PLoS ONE 6, e18757. doi:10.1371/journal.pone.0018757

D'Costa, A. P., Lenham, J. E., Ingram, R. L., and Sonntag, W. E. (1993). Moderate caloric restriction increases type 1 IGF receptors and protein synthesis in aging rats. Mech. Ageing Dev. 71, 59-71.

De Bruin, J. P., Gosden, R. G., Finch, C. E., and Leaman, B. M. (2004). Ovarian aging in two species of long-lived rockfish, Sebastes aleutianus and S. alutus. Biol. Reprod. 71, 1036-1042.

De Magalhaes, J. P., Costa, J., and Church, G. M. (2007). An analysis of the relationship between metabolism, developmental schedules, and longevity using phylogenetic independent contrasts. J. Gerontol. A Biol. Sci. Med. Sci. 62, 149-160.

Di Cicco, E., Tozzini, E. T., Rossi, G., and Cellerino, A. (2011). The short-lived annual fish Nothobranchius furzeri shows a typical teleost aging process reinforced by high incidence of agedependent neoplasias. Exp. Gerontol. 46, 249-256.

Dillin, A., Crawford, D. K., and Kenyon, C. (2002). Timing requirements for insulin/IGF-1 signaling in C. elegans. Science 298, 830-834.

Driver, J. A., Djousse, L., Logroscino, G., Gaziano, J. M., and Kurth, T. (2008). Incidence of cardiovascular disease and cancer in advanced age: prospective cohort study. BMJ 337 , a2467.

Drori, D., and Folman, Y. (1976). Environmental effects on longevity in the male rat: exercise, mating, castration and restricted feeding. Exp. Gerontol. 11, 25-32.

Du, J., Peng, T., Scheidegger, K. J., and Delafontaine, P. (1999). Angiotensin II activation of insulin-like growth factor 1 receptor transcription is mediated by a tyrosine kinasedependent redox-sensitive mechanism. Arterioscler. Thromb. Vasc. Biol. 19, 2119-2126.

Duan, C. (1998). Nutritional and developmental regulation of insulin-like growth factors in fish. J. Nutr. 128, 306S-314S.

Duan, C., and Xu, Q. (2005). Roles of insulin-like growth factor (IGF) binding proteins in regulating IGF actions. Gen. Comp. Endocrinol. 142, 44-52.

Dubrovsky, E. B. (2005). Hormonal cross talk in insect development. Trends Endocrinol. Metab. 16, 6-11.

Dunn, C. W., Hejnol, A., Matus, D. Q., Pang, K., Browne, W. E., Smith, S. A., Seaver, E., Rouse, G. W., Obst, M., Edgecombe, G. D., Sorensen, M. V., Haddock, S. H., Schmidt-Rhaesa, A., Okusu, A., Kristensen, R. M., Wheeler, W. C., Martindale, M. Q., and Giribet, G. (2008). Broad phylogenomic sampling improves resolution of the animal tree of life. Nature 452, 745-749.

Durieux, J., Wolff, S., and Dillin, A. (2011). The cell-non-autonomous nature of electron transport chainmediated longevity. Cell 144, 79-91.

Edrey, Y. H., Park, T. J., Kang, H., Biney, A., and Buffenstein, R. (2011). Endocrine function and neurobiology of the longest-living rodent, the naked mole-rat. Exp. Gerontol. 46, 116-123.

Enomoto, M., Adachi, H., Fukami, A., Furuki, K., Satoh, A., Otsuka, M., Kumagae, S., Nanjo, Y., Shigetoh, Y., and Imaizumi, T. (2008). Serum dehydroepiandrosterone sulfate levels predict longevity in men: 27-year follow-up study in a community-based cohort (Tanushimaru study). J. Am. Geriatr. Soc. 56, 994-998.

Ershler, W. B., Sun, W. H., Binkley, N., Gravenstein, S., Volk, M. J., Kamoske, G., Klopp, R. G., Roecker, E. B., Daynes, R. A., and Weindruch, R. (1993). Interleukin-6 and aging: blood levels and mononuclear cell production increase with advancing age and in vitro production is modifiable by dietary restriction. Lymphokine Cytokine Res. 12, 225-230.

Eto, H., Miyata, M., Shirasawa, T., Akasaki, Y., Hamada, N., Nagaki, A., Orihara, K., Biro, S., and Tei, C. (2008). The long-term effect of angiotensin II type 1a receptor deficiency on hypercholesterolemiainduced atherosclerosis. Hypertens. Res. 31, 1631-1642.

Everitt, A. V., and Cavanagh, L. M. (1965). The ageing process in the hypophysectiomised rat. Gerontologia 11, 198-207.

Fagerlund, U. H., and Donaldson, E. M. (1969). The effect of androgens on the distribution and secretion of cortisol in gonadectomized male sockeye salmon (Oncorhynchus nerka). Gen. Comp. Endocrinol. 12, 438-448.

Fanestil, D. D., and Barrows, C. H. Jr. (1965). Aging in the rotifer. J. Gerontol. 20, 462-469.

Feldman, H. A., Longcope, C., Derby, C. A., Johannes, C. B., Araujo, A. B., Coviello, A. D., Bremner, W. J., and Mckinlay, J. B. (2002). Age trends in the level of serum testosterone and other hormones in middle-aged men: longitudinal results from the Massachusetts male aging study. J. Clin. Endocrinol. Metab. 87, 589-598.

Fenton, M., Huang, H. L., Hong, Y., Hawe, E., Kurz, D. J., and Erusalimsky, J. D. (2004). Early atherogenesis in senescence-accelerated mice. Exp. Gerontol. 39, 115-122.

Ferrucci, L., Corsi, A., Lauretani, F., Bandinelli, S., Bartali, B., Taub, D. D., Guralnik, J. M., and Longo, D. L. (2005). The origins of age-related proinflammatory state. Blood 105, 2294-2299.

Fichter, M. M., Pirke, K. M., and Holsboer, F. (1986). Weight loss causes neuroendocrine disturbances: experimental study in healthy starving subjects. Psychiatry Res. 17, 61-72. 
Fischer, F., Schulte, H., Mohan, S., Tataru, M. C., Kohler, E., Assmann, G., and Von Eckardstein, A. (2004). Associations of insulin-like growth factors, insulin-like growth factor binding proteins and acid-labile subunit with coronary heart disease. Clin. Endocrinol. (Oxf.) 61, 595-602.

Fisher, A. L., and Lithgow, G. J. (2006). The nuclear hormone receptor DAF-12 has opposing effects on Caenorhabditis elegans lifespan and regulates genes repressed in multiple long-lived worms. Aging Cell 5, 127-138.

Flatt, T., and Kawecki, T. J. (2007). Juvenile hormone as a regulator of the trade-off between reproduction and life span in Drosophila melanogaster. Evolution 61, 1980-1991.

Flatt, T., Min, K. J., D’Alterio, C., VillaCuesta, E., Cumbers, J., Lehmann, R., Jones, D. L., and Tatar, M. (2008). Drosophila germ-line modulation of insulin signaling and lifespan. Proc. Natl. Acad. Sci. U.S.A. 105, 6368-6373.

Flood, C., Gherondache, C., Pincus, G., Tait, J. F., Tait, S. A., and Willoughby, S. (1967). The metabolism and secretion of aldosterone in elderly subjects. J. Clin. Invest. 46, 960-966.

Fluri, P., Lüscher, M., Wille, H., and Gerig, L. (1982). Changes in weight of the pharyngeal gland and haemolymph titres of juvenile hormone, protein and vitellogenin in worker honey bees. J. Insect Physiol. 28, 61-68.

Flurkey, K., Papaconstantinou, J., Miller, R. A., and Harrison, D. E. (2001). Lifespan extension and delayed immune and collagen aging in mutant mice with defects in growth hormone production. Proc. Natl. Acad. Sci. U.S.A. 98, 6736-6741.

Fontana, L., and Klein, S. (2007). Aging, adiposity, and calorie restriction. JAMA 297, 986-994.

Fontana, L., Klein, S., Holloszy, J. O., and Premachandra, B. N. (2006). Effect of long-term calorie restriction with adequate protein and micronutrients on thyroid hormones. J. Clin. Endocrinol. Metab. 91, 3232-3235.

Fontana, L., Meyer, T. E., Klein, S., and Holloszy, J. O. (2004). Long-term calorie restriction is highly effective in reducing the risk for atherosclerosis in humans. Proc. Natl. Acad. Sci. U.S.A. 101, 6659-6663.

Fontana, L., Weiss, E. P., Villareal, D. T., Klein, S., and Holloszy, J. O. (2008). Long-term effects of calorie or protein restriction on serum IGF-1 and IGFBP-3 concentration in humans. Aging Cell 7, 681-687.

Fraze, E., Chiou, Y. A., Chen, Y. D., and Reaven, G. M. (1987). Age-related changes in postprandial plasma glucose, insulin, and free fatty acid concentrations in nondiabetic individuals. J. Am. Geriatr. Soc. 35, 224-228.

Friedman, D. B., and Johnson, T. E. (1988). Three mutants that extend both mean and maximum life span of the nematode, Caenorhabditis elegans, define the age-1 gene. J. Gerontol. 43, B102-B109.

Friedrich, N., Haring, R., Nauck, M., Ludemann, J., Rosskopf, D., SpilckeLiss, E., Felix, S. B., Dorr, M., Brabant, G., Volzke, H., and Wallaschofski, H. (2009). Mortality and serum insulin-like growth factor (IGF)-I and IGF binding protein 3 concentrations. J. Clin. Endocrinol. Metab. 94, 1732-1739.

Friedrich, N., Schneider, H., Dorr, M. Nauck, M., Volzke, H., Klotsche, J., Sievers, C., Pittrow, D., Bohler, S., Lehnert, H., Pieper, L., Wittchen, H. U., Wallaschofski, H., and Stalla, G. K. (2011). All-cause mortality and serum insulin-like growth factor I in primary care patients. Growth Horm. IGF Res. 21, 102-106.

Frystyk, J., Skjaerbaek, C., Dinesen, B., and Orskov, H. (1994). Free insulinlike growth factors (IGF-I and IGFII) in human serum. FEBS Lett. 348, 185-191.

Furukuma, S., Onuma, T., Swanson, P., Luo, Q., Koide, N., Okada, H., Urano, A., and Ando, H. (2008). Stimulatory effects of insulin-like growth factor 1 on expression of gonadotropin subunit genes and release of folliclestimulating hormone and luteinizing hormone in masu salmon pituitary cells early in gametogenesis. Zool. Sci. 25, 88-98.

Galic, S., Oakhill, J. S., and Steinberg, G. R. (2010). Adipose tissue as an endocrine organ. Mol. Cell. Endocrinol. 316, 129-139.

Galikova, M., Klepsatel, P., Senti, G., and Flatt, T. (2011). Steroid hormone regulation of $C$. elegans and Drosophila aging and life history. Exp. Gerontol. 46, 141-147.

Galkina, E., and Ley, K. (2009). Immune and inflammatory mechanisms of atherosclerosis (*). Annu. Rev. Immunol. 27, 165-197.

Gems, D., Sutton, A. J., Sundermeyer, M. L., Albert, P. S., King, K. V., Edgley, M. L., Larsen, P. L., and Riddle, D. L. (1998). Two pleiotropic classes of daf-2 mutation affect larval arrest, adult behavior, reproduction and longevity in Caenorhabditis elegans. Genetics 150, 129-155.

Genade, T., Benedetti, M., Terzibasi, E., Roncaglia, P., Valenzano, D. R., Cattaneo, A., and Cellerino, A. (2005). Annual fishes of the genus Nothobranchius as a model system for aging research. Aging Cell 4, 223-233.

Gerhard, G. S., Kauffman, E. J., Wang, X., Stewart, R., Moore, J. L., Kasales, C. J., Demidenko, E., and Cheng, K. C. (2002). Life spans and senescent phenotypes in two strains of zebrafish (Danio rerio). Exp. Gerontol. 37, 1055-1068.

Gerisch, B., Rottiers, V., Li, D., Motola, D. L., Cummins, C. L., Lehrach, H. Mangelsdorf, D. J., and Antebi, A. (2007). A bile acid-like steroid modulates Caenorhabditis elegans lifespan through nuclear receptor signaling. Proc. Natl. Acad. Sci. U.S.A. 104, 5014-5019.

Gerisch, B., Weitzel, C., KoberEisermann, C., Rottiers, V., and Antebi, A. (2001). A hormonal signaling pathway influencing $C$. elegans metabolism, reproductive development, and life span. Dev. Cell 1, 841-851.

Ghazi, A., Henis-Korenblit, S., and Kenyon, C. (2009). A transcription elongation factor that links signals from the reproductive system to lifespan extension in Caenorhabditis elegans. PLoS Genet. 5, el000639. doi:10.1371/journal.pgen.1000639

Giannakou, M. E., Goss, M., Jacobson, J., Vinti, G., Leevers, S. J., and Partridge, L. (2007). Dynamics of the action of dFOXO on adult mortality in Drosophila. Aging Cell 6, 429-438.

Giannakou, M. E., Goss, M., Junger, M. A., Hafen, E., Leevers, S. J., and Partridge, L. (2004). Longlived Drosophila with overexpressed dFOXO in adult fat body. Science 305,361 .

Golden, J. W., and Riddle, D. L. (1984). The Caenorhabditis elegans dauer larva: developmental effects of pheromone, food, and temperature. Dev. Biol. 102, 368-378.

Gomez-Perez, Y., Gianotti, M., Proenza, A. M., and Llado, I. (2011). Agerelated decline of skeletal muscle insulin sensitivity in rats: effect of sex and muscle type. Rejuvenation Res. 14, 153-161.

Gordon, L. B., Harten, I. A., Patti, M. E., and Lichtenstein, A. H. (2005). Reduced adiponectin and HDL cholesterol without elevated Creactive protein: clues to the biology of premature atherosclerosis in Hutchinson-Gilford progeria syndrome. J. Pediatr. 146, 336-341.

Gould, A. L., Rossouw, J. E., Santanello, N. C., Heyse, J. F., and Furberg, C. D. (1998). Cholesterol reduction yields clinical benefit: impact of statin trials. Circulation 97, 946-952.

Grandison, R. C., Piper, M. D., and Partridge, L. (2009). Amino-acid imbalance explains extension of lifespan by dietary restriction in Drosophila. Nature 462, 1061-1064.

Greenstein, B. D., Fitzpatrick, F. T., Adcock, I. M., Kendall, M. D., and Wheeler, M. J. (1986). Reappearance of the thymus in old rats after orchidectomy: inhibition of regeneration by testosterone. J. Endocrinol. 110, 417-422.

Gronke, S., Clarke, D. F., Broughton, S., Andrews, T. D., and Partridge, L. (2010). Molecular evolution and functional characterization of Drosophila insulin-like peptides. PLoS Genet. 6, e1000857. doi:10.1371/journal.pgen.1000857

Groop, L. C. (1999). Insulin resistance: the fundamental trigger of type 2 diabetes. Diabetes Obes. Metab. 1(Suppl. 1), S1-S7.

Guidugli, K. R., Nascimento, A. M., Amdam, G. V., Barchuk, A. R., Omholt, S., Simoes, Z. L., and Hartfelder, K. (2005). Vitellogenin regulates hormonal dynamics in the worker caste of a eusocial insect. FEBS Lett. 579, 4961-4965.

Gunter, M. J., Hoover, D. R., Yu, H., Wassertheil-Smoller, S., Rohan, T. E., Manson, J. E., Li, J., Ho, G. Y., Xue, X., Anderson, G. L., Kaplan, R. C., Harris, T. G., Howard, B. V., WylieRosett, J., Burk, R. D., and Strickler, H. D. (2009). Insulin, insulin-like growth factor-I, and risk of breast cancer in postmenopausal women. J. Natl. Cancer Inst. 101, 48-60.

Haber, C. (2004). Life extension and history: the continual search for the fountain of youth. J. Gerontol. A Biol. Sci. Med. Sci. 59, B515-B522.

Hager, K., Machein, U., Krieger, S., Platt, D., Seefried, G., and Bauer, J. (1994). Interleukin-6 and selected plasma proteins in healthy persons of different ages. Neurobiol. Aging $15,771-772$.

Hamilton, J. B., and Mestler, G. E. (1969). Mortality and survival: comparison of eunuchs with intact men and women in a mentally retarded population. J. Gerontol. 24, 395-411.

Hane, S., and Robertson, O. H. (1959). Changes in plasma 17hydroxycorticosteroids accompanying sexual maturation and spawning of the pacific salmon (Oncorhynchus tshawytscha) and rainbow trout (Salmo gairdnerii). Proc. Natl. Acad. Sci. U.S.A. 45, 886-893.

Hankinson, S. E., Willett, W. C., Colditz, G. A., Hunter, D. J., Michaud, D. S., Deroo, B., Rosner, B., Speizer, F. E., and Pollak, M. (1998). Circulating concentrations of insulin-like growth factor-I and risk of breast cancer. Lancet 351, 1393-1396.

Harman, D. (1956). Aging: a theory based on free radical and radiation chemistry. J. Gerontol. 11, 298-300. 
Harrington, S. C., Simari, R. D., and Conover, C. A. (2007). Genetic deletion of pregnancy-associated plasma protein-A is associated with resistance to atherosclerotic lesion development in apolipoprotein Edeficient mice challenged with a high-fat diet. Circ. Res. 100, 1696-1702.

Harrison, D. E. (1975a). Defective erythropoietic responses of aged mice not improved by young marrow. $J$. Gerontol. 30, 286-288.

Harrison, D. E. (1975b). Normal function of transplanted marrow cell lines from aged mice. J. Gerontol. 30, 279-285.

Heider, P., Pfaffle, N., Pelisek, J., Wildgruber, M., Poppert, H., Rudelius, M., and Eckstein, H. H. (2010). Is serum pregnancy-associated plasma protein A really a potential marker of atherosclerotic carotid plaque stability? Eur. J. Vasc. Endovasc. Surg. 39, 668-675.

Heilbronn, L. K., De Jonge, L., Frisard, M. I., Delany, J. P., LarsonMeyer, D. E., Rood, J., Nguyen, T., Martin, C. K., Volaufova, J., Most, M. M., Greenway, F. L., Smith, S. R., Deutsch, W. A., Williamson, D. A., and Ravussin, E. (2006). Effect of 6-month calorie restriction on biomarkers of longevity, metabolic adaptation, and oxidative stress in overweight individuals: a randomized controlled trial. JAMA 295, 1539-1548.

Hennekam, R. C. (2006). HutchinsonGilford progeria syndrome: review of the phenotype. Am. J. Med. Genet. A 140, 2603-2624.

Herlihy, J. T., Stacy, C., and Bertrand, H. A. (1990). Long-term food restriction depresses serum thyroid hormone concentrations in the rat. Mech. Ageing Dev. 53, 9-16.

Herman, W. S., and Tatar, M. (2001). Juvenile hormone regulation of longevity in the migratory monarch butterfly. Proc. Biol. Sci. 268, 2509-2514.

Hesch, R. D., Gatz, J., Juppner, H., and Stubbe, P. (1977). TBG-dependency of age related variations of thyroxine and triiodothyronine. Horm. Metab. Res. 9, 141-146.

Ho, K. Y., Evans, W. S., Blizzard, R. M., Veldhuis, J. D., Merriam, G. R., Samojlik, E., Furlanetto, R., Rogol, A. D., Kaiser, D. L., and Thorner, M. O. (1987). Effects of sex and age on the 24-hour profile of growth hormone secretion in man: importance of endogenous estradiol concentrations. J. Clin. Endocrinol. Metab. 64, 51-58.

Hoffmann, F. G., and Opazo, J. C. (2011). Evolution of the relaxin/insulin-like gene family in placental mammals: implications for its early evolution. J. Mol. Evol. 72, 72-79.

Holloszy, J. O., and Smith, E. K. (1986). Longevity of cold-exposed rats: a reevaluation of the "rate-ofliving theory." J. Appl. Physiol. 61, 1656-1660.

Holzenberger, M., Dupont, J., Ducos, B., Leneuve, P., Geloen, A., Even, P. C., Cervera, P., and Le Bouc, Y. (2003). IGF-1 receptor regulates lifespan and resistance to oxidative stress in mice. Nature 421,182-187.

Houthoofd, K., Braeckman, B. P., Johnson, T. E., and Vanfleteren, J. R. (2003). Life extension via dietary restriction is independent of the Ins/IGF-1 signalling pathway in Caenorhabditis elegans. Exp. Gerontol. 38, 947-954.

Hsin, H., and Kenyon, C. (1999). Signals from the reproductive system regulate the lifespan of C. elegans. Nature 399, 362-366.

Hsu, S. Y., Nakabayashi, K., Nishi, S., Kumagai, J., Kudo, M., Sherwood, O. D., and Hsueh, A. J. (2002). Activation of orphan receptors by the hormone relaxin. Science 295, 671-674.

Hu, D., Pawlikowska, L., Kanaya, A. Hsueh, W. C., Colbert, L., Newman, A. B., Satterfield, S., Rosen, C., Cummings, S. R., Harris, T. B., and Ziv, E. (2009). Serum insulin-like growth factor-1 binding proteins 1 and 2 and mortality in older adults: the Health, Aging, and Body Composition Study. J. Am. Geriatr. Soc. 57, 1213-1218.

Hulbert, A. J., Clancy, D. J., Mair, W., Braeckman, B. P., Gems, D., and Partridge, L. (2004). Metabolic rate is not reduced by dietary-restriction or by lowered insulin/IGF-1 signalling and is not correlated with individual lifespan in Drosophila melanogaster. Exp. Gerontol. 39, 1137-1143.

Hwangbo, D. S., Gershman, B., Tu, M. P., Palmer, M., and Tatar, M. (2004). Drosophila dFOXO controls lifespan and regulates insulin signalling in brain and fat body. Nature 429, 562-566.

Ikeno, Y., Bronson, R. T., Hubbard, G. B., Lee, S., and Bartke, A. (2003). Delayed occurrence of fatal neoplastic diseases in ames dwarf mice: correlation to extended longevity. $J$. Gerontol. A Biol. Sci. Med. Sci. 58, 291-296.

Ikeno, Y., Hubbard, G. B., Lee, S., Cortez, L. A., Lew, C. M., Webb, C. R., Berryman, D. E., List, E. O., Kopchick, J. J., and Bartke, A. (2009). Reduced incidence and delayed occurrence of fatal neoplastic diseases in growth hormone receptor/binding protein knockout mice. J. Gerontol. A Biol. Sci. Med. Sci. 64, 522-529.
Ikeya, T., Galic, M., Belawat, P., Nairz, K., and Hafen, E. (2002). Nutrientdependent expression of insulin-like peptides from neuroendocrine cells in the CNS contributes to growth regulation in Drosophila. Curr. Biol. 12, 1293-1300.

Imura, A., Iwano, A., Tohyama, O., Tsuji, Y., Nozaki, K., Hashimoto, N., Fujimori, T., and Nabeshima, Y. (2004). Secreted Klotho protein in sera and CSF: implication for posttranslational cleavage in release of Klotho protein from cell membrane. FEBS Lett. 565, 143-147.

Ishibashi, S., Goldstein, J. L., Brown, M. S., Herz, J., and Burns, D. K. (1994). Massive xanthomatosis and atherosclerosis in cholesterolfed low density lipoprotein receptornegative mice. J. Clin. Invest. 93 1885-1893.

Jacobsen, B. K., Knutsen, S. F., and Fraser, G. E. (1999). Age at natural menopause and total mortality and mortality from ischemic heart disease: the Adventist Health Study. J. Clin. Epidemiol. 52, 303-307.

Janssen, J. A., Stolk, R. P., Pols, H. A., Grobbee, D. E., De Jong, F. H., and Lamberts, S. W. (1998). Serum free IGF-I, total IGF-I, IGFBP-1 and IGFBP-3 levels in an elderly population: relation to age and sex steroid levels. Clin. Endocrinol. (Oxf.) 48, 471-478.

Jaycox, E. R., Skowronek, W., and Guynn, G. (1974). Behavioural changes in worker honey bees induced by injections of a juvenile hormone mimic. Ann. Entomol. Soc. Am. 67 529-534.

Jensen, H. K., and Blichert-Toft, M. (1971). Serum corticotrophin, plasma cortisol and urinary excretion of 17-ketogenic steroids in the elderly (age group: 66-94 years). Acta Endocrinol. 66, 25-34.

Jia, K., Albert, P. S., and Riddle, D. L. (2002). DAF-9, a cytochrome P450 regulating C. elegans larval development and adult longevity. Development 129, 221-231.

Johanson, A. J., and Blizzard, R. M. (1981). Low somatomedin-C levels in older men rise in response to growth hormone administration. Johns Hopkins Med. J. 149, 115-117.

Johnsen, S. P., Hundborg, H. H., Sorensen, H. T., Orskov, H., Tjonneland, A., Overvad, K., and Jorgensen, J. O. (2005). Insulin-like growth factor (IGF) I, -II, and IGF binding protein-3 and risk of ischemic stroke. J. Clin. Endocrinol. Metab. 90, 5937-5941.

Juul, A., Holm, K., Kastrup, K. W. Pedersen, S. A., Michaelsen, K. F., Scheike, T., Rasmussen, S., Muller, J., and Skakkebaek, N. E. (1997). Free insulin-like growth factor I serum levels in 1430 healthy children and adults, and its diagnostic value in patients suspected of growth hormone deficiency. J. Clin. Endocrinol. Metab. 82, 2497-2502.

Juul, A., Scheike, T., Davidsen, M., Gyllenborg, J., and Jorgensen, T. (2002). Low serum insulin-like growth factor I is associated with increased risk of ischemic heart disease: a population-based case-control study. Circulation 106, 939-944.

Kaplan, R. C., Mcginn, A. P., Pollak, M. N., Kuller, L., Strickler, H. D. Rohan, T. E., Xue, X., Kritchevsky, S. B., Newman, A. B., and Psaty, B. M. (2008). Total insulinlike growth factor 1 and insulinlike growth factor binding protein levels, functional status, and mortality in older adults. J. Am. Geriatr. Soc. 56, 652-660.

Katic, M., Kennedy, A. R., Leykin, I., Norris, A., Mcgettrick, A., Gesta, S., Russell, S. J., Bluher, M., MaratosFlier, E., and Kahn, C. R. (2007). Mitochondrial gene expression and increased oxidative metabolism: role in increased lifespan of fat-specific insulin receptor knock-out mice. Aging Cell 6, 827-839.

Kawachi, S., Takeda, N., Sasaki, A., Kokubo, Y., Takami, K., Sarui, H., Hayashi, M., Yamakita, N., and Yasuda, K. (2005). Circulating insulin-like growth factor-1 and insulin-like growth factor binding protein-3 are associated with early carotid atherosclerosis. Arterioscler. Thromb. Vasc. Biol. 25, 617-621.

Keller, L., and Genoud, M. (1997). Extraordinary lifespans in ants: a test of evolutionary theories of ageing. Nature 389, 958-960.

Kenyon, C. (2010). A pathway that links reproductive status to lifespan in Caenorhabditis elegans. Ann. N. Y. Acad. Sci. 1204, 156-162.

Kenyon, C., Chang, J., Gensch, E., Rudner, A., and Tabtiang, R. (1993). A C. elegans mutant that lives twice as long as wild type. Nature 366, 461-464.

Kimura, K. D., Tissenbaum, H. A., Liu, Y., and Ruvkun, G. (1997). daf-2, an insulin receptor-like gene that regulates longevity and diapause in Caenorhabditis elegans. Science 277, 942-946.

Klass, M. R. (1977). Aging in the nematode Caenorhabditis elegans: major biological and environmental factors influencing life span. Mech. Ageing Dev. 6, 413-429.

Klass, M. R. (1983). A method for the isolation of longevity mutants in the nematode Caenorhabditis elegans and initial results. Mech. Ageing Dev. 22, 279-286. 
Koster, A., Stenholm, S., Alley, D. E., Kim, L. J., Simonsick, E. M., Kanaya, A. M., Visser, M., Houston, D. K., Nicklas, B. J., Tylavsky, F. A., Satterfield, S., Goodpaster, B. H., Ferrucci, L., and Harris, T. B. (2010). Body fat distribution and inflammation among obese older adults with and without metabolic syndrome. Obesity (Silver Spring) 18, 2354-2361.

Kramer, B., and Buffenstein, R. (2004). The pancreas of the naked molerat (Heterocephalus glaber): an ultrastructural and immunocytochemical study of the endocrine component of thermoneutral and cold acclimated animals. Gen. Comp. Endocrinol. 139, 206-214.

Kuhn, H. G., Dickinson-Anson, H., and Gage, F. H. (1996). Neurogenesis in the dentate gyrus of the adult rat: age-related decrease of neuronal progenitor proliferation. J. Neurosci. 16, 2027-2033.

Kuk, J. L., Saunders, T. J., Davidson, L. E., and Ross, R. (2009). Agerelated changes in total and regional fat distribution. Ageing Res. Rev. 8, 339-348.

Kuningas, M., Magi, R., Westendorp, R. G., Slagboom, P. E., Remm, M., and Van Heemst, D. (2007). Haplotypes in the human Foxola and Foxo3a genes; impact on disease and mortality at old age. Eur. J. Hum. Genet. 15, 294-301.

Kuro-O, M., Matsumura, Y., Aizawa, H., Kawaguchi, H., Suga, T., Utsugi, T., Ohyama, Y., Kurabayashi, M., Kaname, T., Kume, E., Iwasaki, H., Iida, A., Shiraki-Iida, T., Nishikawa, S., Nagai, R., and Nabeshima, Y. I. (1997). Mutation of the mouse klotho gene leads to a syndrome resembling ageing. Nature 390, 45-51.

Kurosu, H., Yamamoto, M., Clark, J. D., Pastor, J. V., Nandi, A., Gurnani, P., Mcguinness, O. P., Chikuda, H., Yamaguchi, M., Kawaguchi, H., Shimomura, I., Takayama, Y., Herz, J., Kahn, C. R., Rosenblatt, K. P., and Kuro-O, M. (2005). Suppression of aging in mice by the hormone Klotho. Science 309, 1829-1833.

Lacreuse, A., Chennareddi, L., Gould, K. G., Hawkes, K., Wijayawardana, S. R., Chen, J., Easley, K. A., and Herndon, J. G. (2008). Menstrual cycles continue into advanced old age in the common chimpanzee (Pan troglodytes). Biol. Reprod. 79, 407-412.

Ladiges, W., Van Remmen, H., Strong, R., Ikeno, Y., Treuting, P., Rabinovitch, P., and Richardson, A.
(2009). Lifespan extension in genetically modified mice. Aging Cell 8, 346-352.

Lakatta, E. G., Wang, M., and Najjar, S. S. (2009). Arterial aging and subclinical arterial disease are fundamentally intertwined at macroscopic and molecular levels. Med. Clin. North Am. 93, 583-604.

Lakowski, B., and Hekimi, S. (1998). The genetics of caloric restriction in Caenorhabditis elegans. Proc. Natl. Acad. Sci. U.S.A. 95, 13091-13096.

Lane, M. A., Ball, S. S., Ingram, D. K., Cutler, R. G., Engel, J., Read, V., and Roth, G. S. (1995). Diet restriction in rhesus monkeys lowers fasting and glucose-stimulated glucoregulatory end points. Am. J. Physiol. 268, E941-E948.

Laron, Z. (2005). Do deficiencies in growth hormone and insulin-like growth factor-1 (IGF-1) shorten or prolong longevity? Mech. Ageing Dev. 126, 305-307.

Laughlin, G. A., Barrett-Connor, E., Criqui, M. H., and Kritz-Silverstein, D. (2004). The prospective association of serum insulin-like growth factor I (IGF-I) and IGF-binding protein-1 levels with all cause and cardiovascular disease mortality in older adults: the Rancho Bernardo study. J. Clin. Endocrinol. Metab. 89, 114-120.

Lawrence, J. B., Oxvig, C., Overgaard, M. T., Sottrup-Jensen, L., Gleich, G. J., Hays, L. G., Yates, J. R., 3rd, and Conover, C. A. (1999). The insulin-like growth factor (IGF)dependent IGF binding protein-4 protease secreted by human fibroblasts is pregnancy-associated plasma protein-A. Proc. Natl. Acad. Sci. U.S.A. 96, 3149-3153.

Lee, S. J., Lenton, E. A., Sexton, L., and Cooke, I. D. (1988). The effect of age on the cyclical patterns of plasma LH, FSH, oestradiol and progesterone in women with regular menstrual cycles. Hum. Reprod. 3, 851-855.

Lee, W. L., Chen, J. W., Ting, C. T., Ishiwata, T., Lin, S. J., Korc, M., and Wang, P. H. (1999). Insulin-like growth factor I improves cardiovascular function and suppresses apoptosis of cardiomyocytes in dilated cardiomyopathy. Endocrinology 140, 4831-4840.

Leeper, N. J., Ardehali, R., Degoma, E. M., and Heidenreich, P. A. (2007). Statin use in patients with extremely low low-density lipoprotein levels is associated with improved survival. Circulation 116, 613-618.

Lenton, E. A., Sexton, L., Lee, S., and Cooke, I. D. (1988). Progressive changes in LH and FSH and LH: FSH ratio in women throughout reproductive life. Maturitas 10, 35-43.

Li, M., Chiu, J. F., Gagne, J., and Fukagawa, N. K. (2008). Age-related differences in insulin-like growth factor-1 receptor signaling regulates Akt/FOXO3a and ERK/Fos pathways in vascular smooth muscle cells. $J$. Cell. Physiol. 217, 377-387.

Li, Q., and Ren, J. (2007). Influence of cardiac-specific overexpression of insulin-like growth factor 1 on lifespan and aging-associated changes in cardiac intracellular $\mathrm{Ca} 2+$ homeostasis, protein damage and apoptotic protein expression. Aging Cell 6, 799-806.

Li, W., Kennedy, S. G., and Ruvkun, G. (2003). daf-28 encodes a C. elegans insulin superfamily member that is regulated by environmental cues and acts in the DAF-2 signaling pathway. Genes Dev. 17, 844-858.

Li, Y., Wang, W. J., Cao, H., Lu, J., Wu, C., Hu, F. Y., Guo, J., Zhao, L., Yang, F., Zhang, Y. X., Li, W., Zheng, G. Y., Cui, H., Chen, X., Zhu, Z., He, H., Dong, B., Mo, X., Zeng, Y., and Tian, X. L. (2009). Genetic association of FOXO1A and FOXO3A with longevity trait in Han Chinese populations. Hum. Mol. Genet. 18, 4897-4904.

Li, Z., Froehlich, J., Galis, Z. S. and Lakatta, E. G. (1999). Increased expression of matrix metalloproteinase- 2 in the thickened intima of aged rats. Hypertension 33, 116-123.

Libert, S., Zwiener, J., Chu, X., Vanvoorhies, W., Roman, G., and Pletcher, S. D. (2007). Regulation of Drosophila life span by olfaction and food-derived odors. Science 315, 1133-1137.

Libina, N., Berman, J. R., and Kenyon, C. (2003). Tissue-specific activities of C. elegans DAF-16 in the regulation of lifespan. Cell 115, 489-502.

Lim, S., Yoon, J. W., Choi, S. H., Park, Y. J., Lee, J. J., Park, J. H., Lee, S. B., Kim, K. W., Lim, J. Y., Kim, Y. B. Park, K. S., Lee, H. K., Cho, S. I., and Jang, H. C. (2010). Combined impact of adiponectin and retinolbinding protein 4 on metabolic syndrome in elderly people: the Korean Longitudinal Study on Health and Aging. Obesity (Silver Spring) 18, 826-832.

Lin, K., Hsin, H., Libina, N., and Kenyon, C. (2001). Regulation of the Caenorhabditis elegans longevity protein DAF-16 by insulin/IGF-1 and germline signaling. Nat. Genet. 28, 139-145.

Lindsay, R., Bush, T. L., Grady, D., Speroff, L., and Lobo, R. A. (1996). Therapeutic controversy: estrogen replacement in menopause. J. Clin. Endocrinol. Metab. 81, 3829-3838.

Liu, H., Fergusson, M. M., Castilho, R. M., Liu, J., Cao, L., Chen, J., Malide, D., Rovira, Ii, Schimel, D., Kuo, C. J., Gutkind, J. S., Hwang, P. M., and Finkel, T. (2007). Augmented Wnt signaling in a mammalian model of accelerated aging. Science 317, 803-806.

Liu, J. L., and Leroith, D. (1999). Insulin-like growth factor I is essential for postnatal growth in response to growth hormone. Endocrinology 140, 5178-5184.

Liu, J. P., Baker, J., Perkins, A. S., Robertson, E. J., and Efstratiadis, A. (1993). Mice carrying null mutations of the genes encoding insulin-like growth factor I (Igf-1) and type 1 IGF receptor (Igf1r). Cell 75, 59-72.

Liu, X., Jiang, N., Hughes, B., Bigras, E., Shoubridge, E., and Hekimi, S. (2005). Evolutionary conservation of the clk-1-dependent mechanism of longevity: loss of mclk1 increases cellular fitness and lifespan in mice. Genes Dev. 19, 2424-2434.

Lund, J., Qin, Q. P., Ilva, T., Pettersson, K., Voipio-Pulkki, L. M., Porela, P., and Pulkki, K. (2003). Circulating pregnancy-associated plasma protein a predicts outcome in patients with acute coronary syndrome but no troponin I elevation. Circulation 108, 1924-1926.

Ma, J., Pollak, M. N., Giovannucci, E., Chan, J. M., Tao, Y., Hennekens, C. H., and Stampfer, M. J. (1999). Prospective study of colorectal cancer risk in men and plasma levels of insulin-like growth factor (IGF)-I and IGF-binding protein-3. J. Natl. Cancer Inst. 91, 620-625.

Mabuchi, H., Miyamoto, S., Ueda, K., Oota, M., Takegoshi, T., Wakasugi, T., and Takeda, R. (1986). Causes of death in patients with familial hypercholesterolemia. Atherosclerosis 61, 1-6.

Maestro, M. A., Planas, J. V., Moriyama, S., Gutierrez, J., Planas, J., and Swanson, P. (1997). Ovarian receptors for insulin and insulin-like growth factor I (IGF-I) and effects of IGF-I on steroid production by isolated follicular layers of the preovulatory coho salmon ovarian follicle. Gen. Comp. Endocrinol. 106, 189-201.

Mair, W., Goymer, P., Pletcher, S. D., and Partridge, L. (2003). Demography of dietary restriction and death in Drosophila. Science 301, 1731-1733.

Major, J. M., Laughlin, G. A., KritzSilverstein, D., Wingard, D. L., and Barrett-Connor, E. (2010). Insulinlike growth factor-I and cancer mortality in older men. J. Clin Endocrinol. Metab. 95, 1054-1059. 
Maldonado, T. A., Jones, R. E., and Norris, D. O. (2000). Distribution of beta-amyloid and amyloid precursor protein in the brain of spawning (senescent) salmon: a natural, brain-aging model. Brain Res. 858, 237-251.

Maldonado, T. A., Jones, R. E., and Norris, D. O. (2002). Timing of neurodegeneration and beta-amyloid (Abeta) peptide deposition in the brain of aging kokanee salmon. J. Neurobiol. 53, 21-35.

Mallatt, J., and Winchell, C. J. (2002). Testing the new animal phylogeny: first use of combined largesubunit and small-subunit rRNA gene sequences to classify the protostomes. Mol. Biol. Evol. 19, 289-301.

Mangel, M., Kindsvater, H. K., and Bonsall, M. B. (2007). Evolutionary analysis of life span, competition, and adaptive radiation, motivated by the Pacific rockfishes (Sebastes). Evolution 61, 1208-1224.

Margolis, J., and Spradling, A. (1995). Identification and behavior of epithelial stem cells in the Drosophila ovary. Development 121,3797-3807.

Mariotti, S., Franceschi, C., Cossarizza, A., and Pinchera, A. (1995). The aging thyroid. Endocr. Rev. 16, 686-715.

Maslov, A. Y., Barone, T. A., Plunkett, R. J., and Pruitt, S. C. (2004). Neural stem cell detection, characterization, and age-related changes in the subventricular zone of mice. J. Neurosci. 24, 1726-1733.

Mason, J. B., Cargill, S. L., Anderson, G. B., and Carey, J. R. (2009). Transplantation of young ovaries to old mice increased life span in transplant recipients. J. Gerontol. A Biol. Sci. Med. Sci. 64, 1207-1211.

Mason, J. B., Cargill, S. L., Griffey, S. M., Reader, J. R., Anderson, G. B., and Carey, J. R. (2011). Transplantation of young ovaries restored cardioprotective influence in postreproductive-aged mice. Aging Cell 10, 448-456.

Masoro, E. J., Mccarter, R. J., Katz, M. S., and Mcmahan, C. A. (1992). Dietary restriction alters characteristics of glucose fuel use. J. Gerontol. 47, B202-B208.

Mattison, J. A., Lane, M. A., Roth, G. S., and Ingram, D. K. (2003). Calorie restriction in rhesus monkeys. Exp. Gerontol. 38, 35-46.

Mcallan, B. M. (2006). Dasyurid marsupials as models for the physiology of ageing in humans. Aust. J. Zool. 54, 159-172.

Mccay, C. M., Crowell, M. F., and Maynard, L. A. (1935). The effect of retarded growth upon the length of life and upon ultimate size. J. Nutr. 10, 63-79.
Mcdonald, I. R., Lee, A. K., Than, K. A., and Martin, R. W. (1986). Failure of glucocorticoid feedback in males of a population of small marsupials (Antechinus swainsonii) during the period of mating. J. Endocrinol. 108, 63-68.

Mcquillan, H. J., Lokman, P. M., and Young, G. (2003). Effects of sex steroids, sex, and sexual maturity on cortisol production: an in vitro comparison of chinook salmon and rainbow trout interrenals. Gen. Comp. Endocrinol. 133, 154-163.

Medici, D., Razzaque, M. S., Deluca, S., Rector, T. L., Hou, B., Kang, K., Goetz, R., Mohammadi, M., Kuro, O. M., Olsen, B. R., and Lanske, B. (2008). FGF-23-Klotho signaling stimulates proliferation and prevents vitamin $\mathrm{D}$-induced apoptosis. J. Cell Biol. 182, 459-465.

Mehta, P. K., and Griendling, K. K. (2007). Angiotensin II cell signaling: physiological and pathological effects in the cardiovascular system. Am. J. Physiol. Cell Physiol. 292, C82-C97.

Menzaghi, C., Trischitta, V., and Doria, A. (2007). Genetic influences of adiponectin on insulin resistance, type 2 diabetes, and cardiovascular disease. Diabetes 56, 1198-1209.

Messaoudi, I., Warner, J., Fischer, M., Park, B., Hill, B., Mattison, J., Lane, M. A., Roth, G. S., Ingram, D. K., Picker, L. J., Douek, D. C., Mori, M., and Nikolich-Zugich, J. (2006). Delay of $\mathrm{T}$ cell senescence by caloric restriction in aged long-lived nonhuman primates. Proc. Natl. Acad. Sci. U.S.A. 103, 19448-19453.

Micchelli, C. A., and Perrimon, N. (2006). Evidence that stem cells reside in the adult Drosophila midgut epithelium. Nature 439, 475-479.

Miller, R. A. (1991). Gerontology as oncology. Research on aging as the key to the understanding of cancer. Cancer 68, 2496-2501.

Mills, G. L., and Taylaur, C. E. (1971). The distribution and composition of serum lipoproteins in eighteen animals. Comp. Biochem. Physiol. B 40, 489-501.

Morin, C. L., Pagliassotti, M. J., Windmiller, D., and Eckel, R. H. (1997). Adipose tissue-derived tumor necrosis factor-alpha activity is elevated in older rats. J. Gerontol. A Biol. Sci. Med. Sci. 52, B190-B195.

Morley, J. E., Kaiser, F. E., Perry, H. M., 3rd, Patrick, P., Morley, P. M., Stauber, P. M., Vellas, B., Baumgartner, R. N., and Garry, P. J. (1997). Longitudinal changes in testosterone, luteinizing hormone, and follicle-stimulating hormone in healthy older men. Metab. Clin. Exp. 46, 410-413.

Motola, D. L., Cummins, C. L., Rottiers, V., Sharma, K. K., Li, T., Li, Y., SuinoPowell, K., Xu, H. E., Auchus, R. J., Antebi, A., and Mangelsdorf, D. J. (2006). Identification of ligands for DAF-12 that govern dauer formation and reproduction in C. elegans. Cell 124, 1209-1223.

Mulinos, M. G., and Pomerantz, L. (1940). Psuedo-hypophysectomy, a condition resembling hypophysectomy produced by malnutrition. $J$. Nutr. 19, 493-500.

Munch, D., and Amdam, G. V. (2010). The curious case of aging plasticity in honey bees. FEBS Lett. 584, 2496-2503.

Murakami, H., and Murakami, S. (2007). Serotonin receptors antagonistically modulate Caenorhabditis elegans longevity. Aging Cell 6, 483-488.

Murphy, C. T., Lee, S. J., and Kenyon, C. (2007). Tissue entrainment by feedback regulation of insulin gene expression in the endoderm of Caenorhabditis elegans. Proc. Natl. Acad. Sci. U.S.A. 104, 19046-19050.

Muzumdar, R., Allison, D. B., Huffman, D. M., Ma, X., Atzmon, G. Einstein, F. H., Fishman, S., Poduval, A. D., Mcvei, T., Keith, S. W., and Barzilai, N. (2008). Visceral adipose tissue modulates mammalian longevity. Aging Cell 7, 438-440.

Nagai, Y., Metter, E. J., Earley, C. J., Kemper, M. K., Becker, L. C., Lakatta, E. G., and Fleg, J. L. (1998). Increased carotid artery intimal-medial thickness in asymptomatic older subjects with exercise-induced myocardial ischemia. Circulation 98, 1504-1509.

Nakagawa, Y., and Henrich, V. C. (2009). Arthropod nuclear receptors and their role in molting. FEBS J. 276, 6128-6157.

Nakashima, Y., Fujii, H., Sumiyoshi, S., Wight, T. N., and Sueishi, K. (2007). Early human atherosclerosis: accumulation of lipid and proteoglycans in intimal thickenings followed by macrophage infiltration. Arterioscler. Thromb. Vasc. Biol. 27, 1159-1165.

Nakashima, Y., Wight, T. N., and Sueishi, K. (2008). Early atherosclerosis in humans: role of diffuse intimal thickening and extracellular matrix proteoglycans. Cardiovasc. Res. 79, 14-23.

Narasimhan, S. D., Yen, K., Bansal, A., Kwon, E. S., Padmanabhan, S., and Tissenbaum, H. A. (2011). PDP-1 links the TGFbeta and IIS pathways to regulate longevity, development, and metabolism. PLoS Genet. 7, e1001377. doi:10.1371/journal.pgen.1001377

Narimiya, M., Azhar, S., Dolkas, C. B., Mondon, C. E., Sims, C., Wright, D. W., and Reaven, G. M. (1984). Insulin resistance in older rats. Am. J. Physiol. 246, E397-E404.

Nichols, T. C., Busby, W. H. Jr., Merricks, E., Sipos, J., Rowland, M., Sitko, K., and Clemmons, D. R. (2007). Protease-resistant insulinlike growth factor (IGF)-binding protein-4 inhibits IGF-I actions and neointimal expansion in a porcine model of neointimal hyperplasia. Endocrinology 148, 5002-5010.

Nishimura, E. K., Granter, S. R., and Fisher, D. E. (2005). Mechanisms of hair graying: incomplete melanocyte stem cell maintenance in the niche. Science 307, 720-724.

Ohlstein, B., and Spradling, A. (2006). The adult Drosophila posterior midgut is maintained by pluripotent stem cells. Nature 439, 470-474.

Olinski, R. P., Lundin, L. G., and Hallbook, F. (2006). Conserved synteny between the Ciona genome and human paralogons identifies large duplication events in the molecular evolution of the insulin-relaxin gene family. Mol. Biol. Evol. 23, 10-22.

Olive, M., Harten, I., Mitchell, R., Beers, J. K., Djabali, K., Cao, K., Erdos, M. R., Blair, C., Funke, B., Smoot, L., Gerhard-Herman, M., Machan, J. T., Kutys, R., Virmani, R., Collins, F. S., Wight, T. N., Nabel, E. G., and Gordon, L. B. (2010). Cardiovascular pathology in HutchinsonGilford progeria: correlation with the vascular pathology of aging. Arterioscler. Thromb. Vasc. Biol. 30, 2301-2309.

Olivetti, G., Abbi, R., Quaini, F., Kajstura, J., Cheng, W., Nitahara, J. A., Quaini, E., Di Loreto, C., Beltrami, C. A., Krajewski, S., Reed, J. C., and Anversa, P. (1997). Apoptosis in the failing human heart. N. Engl. J. Med. 336, 1131-1141.

Olsen, G. G., and Everitt, A. V. (1965). Retardation of the ageing process in collagen fibres from the tail tendon of the old hypophysectomized rat. Nature 206, 307-308.

Onuma, T. A., Makino, K., Katsumata, H., Beckman, B. R., Ban, M., Ando, H., Fukuwaka, M. A., Azumaya, T., Swanson, P., and Urano, A. (2010). Changes in the plasma levels of insulin-like growth factorI from the onset of spawning migration through upstream migration in chum salmon. Gen. Comp. Endocrinol. 165, 237-243.

Ooka, H., Fujita, S., and Yoshimoto, E. (1983). Pituitary-thyroid activity and longevity in neonatally thyroxine-treated rats. Mech. Ageing Dev. 22, 113-120. 
Orentreich, N., Brind, J. L., Vogelman, J. H., Andres, R., and Baldwin, H. (1992). Long-term longitudinal measurements of plasma dehydroepiandrosterone sulfate in normal men. J. Clin. Endocrinol. Metab. 75, 1002-1004.

Orlandi, A., Marcellini, M., and Spagnoli, L. G. (2000). Aging influences development and progression of early aortic atherosclerotic lesions in cholesterol-fed rabbits. Arterioscler. Thromb. Vasc. Biol. 20, 1123-1136.

Orlandi, A., Mauriello, A., Marino, B., and Spagnoli, L. G. (1993). Agerelated modifications of aorta and coronaries in the rabbit: a morphological and morphometrical assessment. Arch. Gerontol. Geriatr. 17, 37-53.

Paik, J. H., Kollipara, R., Chu, G., Ji, H., Xiao, Y., Ding, Z., Miao, L., Tothova, Z., Horner, J. W., Carrasco, D. R., Jiang, S., Gilliland, D. G., Chin, L., Wong, W. H., Castrillon, D. H., and Depinho, R. A. (2007). FoxOs are lineage-restricted redundant tumor suppressors and regulate endothelial cell homeostasis. Cell 128, 309-323.

Parker, A., Gockerman, A., Busby, W. H., and Clemmons, D. R. (1995). Properties of an insulin-like growth factor-binding protein-4 protease that is secreted by smooth muscle cells. Endocrinology 136, 2470-2476.

Pawlikowska, L., Hu, D., Huntsman, S., Sung, A., Chu, C., Chen, J., Joyner, A. H., Schork, N. J., Hsueh, W. C., Reiner, A. P., Psaty, B. M., Atzmon, G., Barzilai, N., Cummings, S. R., Browner, W. S., Kwok, P. Y., and Ziv, E. (2009). Association of common genetic variation in the insulin/IGF1 signaling pathway with human longevity. Aging Cell 8, 460-472.

Perez, V. I., Bokov, A., Van Remmen, H., Mele, J., Ran, Q., Ikeno, Y., and Richardson, A. (2009). Is the oxidative stress theory of aging dead? Biochim. Biophys. Acta 1790, 1005-1014.

Peterson, P. K., Chao, C. C., Carson, P., Hu, S., Nichol, K., and Janoff, E. N. (1994). Levels of tumor necrosis factor alpha, interleukin 6 , interleukin 10 , and transforming growth factor beta are normal in the serum of the healthy elderly. Clin. Infect. Dis. 19, 1158-1159.

Philipp, E. E., and Abele, D. (2010). Masters of longevity: lessons from long-lived bivalves - a mini-review. Gerontology 56, 55-65.

Pierce, S. B., Costa, M., Wisotzkey, R., Devadhar, S., Homburger, S. A., Buchman, A. R., Ferguson, K. C., Heller, J., Platt, D. M., Pasquinelli, A. A., Liu, L. X., Doberstein, S. K., and
Ruvkun, G. (2001). Regulation of DAF-2 receptor signaling by human insulin and ins-1, a member of the unusually large and diverse $C$. elegans insulin gene family. Genes Dev. $15,672-686$.

Pinkston, J. M., Garigan, D., Hansen, M., and Kenyon, C. (2006). Mutations that increase the life span of C. elegans inhibit tumor growth. Science 313, 971-975.

Pinkston-Gosse, J., and Kenyon, C. (2007). DAF-16/FOXO targets genes that regulate tumor growth in Caenorhabditis elegans. Nat. Genet. 39, 1403-1409.

Pinto, L. Z., Bitondi, M. M., and Simoes, Z. L. (2000). Inhibition of vitellogenin synthesis in Apis mellifera workers by a juvenile hormone analogue, pyriproxyfen. J. Insect Physiol. $46,153-160$.

Pisani, P. (2008). Hyper-insulinaemia and cancer, meta-analyses of epidemiological studies. Arch. Physiol. Biochem. 114, 63-70.

Pistilli, E. E., Jackson, J. R., and Alway, S. E. (2006). Death receptorassociated pro-apoptotic signaling in aged skeletal muscle. Apoptosis 11, 2115-2126.

Plump, A. S., Smith, J. D., Hayek, T., Aalto-Setala, K., Walsh, A., Verstuyft, J. G., Rubin, E. M., and Breslow, J. L. (1992). Severe hypercholesterolemia and atherosclerosis in apolipoprotein E-deficient mice created by homologous recombination in ES cells. Cell 71, 343-353.

Poehlman, E. T., and Copeland, K. C. (1990). Influence of physical activity on insulin-like growth factorI in healthy younger and older men. J. Clin. Endocrinol. Metab. 71, 1468-1473.

Pollak, M. (2008). Insulin and insulinlike growth factor signalling in neoplasia. Nat. Rev. Cancer 8, 915-928.

Powers, R. W., 3rd, Harrison, D. E., and Flurkey, K. (2006). Pituitary removal in adult mice increases life span. Mech. Ageing Dev. 127, 658-659.

Probst-Hensch, N. M., Yuan, J. M., Stanczyk, F. Z., Gao, Y. T., Ross, R. K., and Yu, M. C. (2001). IGF-1, IGF-2 and IGFBP-3 in prediagnostic serum: association with colorectal cancer in a cohort of Chinese men in Shanghai. Br. J. Cancer 85, 1695-1699.

Prothero, J. (1993). Adult life span as a function of age at maturity. Exp. Gerontol. 28, 529-536.

Ramsey, M. M., Ingram, R. L., Cashion, A. B., Ng, A. H., Cline, J. M., Parlow, A. F., and Sonntag, W. E. (2002). Growth hormone-deficient dwarf animals are resistant to dimethylbenzanthracine (DMBA)induced mammary carcinogenesis. Endocrinology 143, 4139-4142.

Ravaglia, G., Forti, P., Maioli, F., Boschi, F., Bernardi, M., Pratelli, L., Pizzoferrato, A., and Gasbarrini, G. (1996). The relationship of dehydroepiandrosterone sulfate (DHEAS) to endocrine-metabolic parameters and functional status in the oldest-old. Results from an Italian study on healthy free-living overninety-year-olds. J. Clin. Endocrinol. Metab. 81, 1173-1178.

Reichwald, K., Lauber, C., Nanda, I., Kirschner, J., Hartmann, N., Schories, S., Gausmann, U., Taudien, S., Schilhabel, M. B., Szafranski, K., Glockner, G., Schmid, M., Cellerino, A., Schartl, M., Englert, C., and Platzer, M. (2009). High tandem repeat content in the genome of the short-lived annual fish Nothobranchius furzeri: a new vertebrate model for aging research. Genome Biol. 10, R16.

Remolina, S. C., Hafez, D. M., Robinson, G. E., and Hughes, K. A. (2007). Senescence in the worker honey bee Apis mellifera. J. Insect Physiol. 53, 1027-1033.

Ren, J., Samson, W. K., and Sowers, J. R. (1999). Insulin-like growth factor I as a cardiac hormone: physiological and pathophysiological implications in heart disease. J. Mol. Cell. Cardiol. 31, 2049-2061.

Renault, V. M., Rafalski, V. A., Morgan, A. A., Salih, D. A., Brett, J. O., Webb, A. E., Villeda, S. A., Thekkat, P. U. Guillerey, C., Denko, N. C., Palmer, T. D., Butte, A. J., and Brunet, A. (2009). FoxO3 regulates neural stem cell homeostasis. Cell Stem Cell 5, 527-539.

Renehan, A. G., Zwahlen, M., Minder, C., O'Dwyer, S. T., Shalet, S. M., and Egger, M. (2004). Insulin-like growth factor (IGF)-I, IGF binding protein-3, and cancer risk: systematic review and meta-regression analysis. Lancet 363, 1346-1353.

Ricklefs, R. E., and Cadena, C. D. (2007) Lifespan is unrelated to investment in reproduction in populations of mammals and birds in captivity. Ecol. Lett. 10, 867-872.

Riddle, D. L., Swanson, M. M., and Albert, P. S. (1981). Interacting genes in nematode dauer larva formation. Nature 290, 668-671.

Robertson, O. H. (1961). Prolongation of the life span of Kokanee salmon (Oncorhynchus nerka kennerlyi) by castration before beginning of gonad development. Proc. Natl. Acad. Sci. U.S.A. 47, 609-621.

Robertson, O. H., Hane, S., Wexler, B. C., and Rinfret, A. P. (1963). The effect of hydrocortisone on immature rainbow trout (Salmo gairdnerii). Gen. Comp. Endocrinol. 18, 422-436.

Robertson, O. H., and Wexler, B. C. (1960). Histological changes in the organs and tissues of migrating and spawning Pacific salmon (genus Oncorhynchus). Endocrinology 66, 222-239.

Robertson, O. H., Wexler, B. C., and Miller, B. F. (1961). Degenerative changes in the cardiovascular system of the spawning Pacific salmon (Oncorhynchus tshawytscha). Circ. Res. 9, 826-834.

Rosen, T., and Bengtsson, B. A. (1990). Premature mortality due to cardiovascular disease in hypopituitarism. Lancet 336, 285-288.

Roth, G. S., Handy, A. M., Mattison, J. A., Tilmont, E. M., Ingram, D. K., and Lane, M. A. (2002). Effects of dietary caloric restriction and aging on thyroid hormones of rhesus monkeys. Horm. Metab. Res. 34, 378-382.

Roubenoff, R., Parise, H., Payette, H. A., Abad, L. W., D’Agostino, R., Jacques, P. F., Wilson, P. W., Dinarello, C. A., and Harris, T. B. (2003). Cytokines, insulin-like growth factor 1, sarcopenia, and mortality in very old community-dwelling men and women: the Framingham Heart Study. Am. J. Med. 115, 429-435.

Rudman, D., Kutner, M. H., Rogers, C. M., Lubin, M. F., Fleming, G. A., and Bain, R. P. (1981). Impaired growth hormone secretion in the adult population: relation to age and adiposity. J. Clin. Invest. 67, 1361-1369.

Rueppell, O., Bachelier, C., Fondrk, M. K., and Page, R. E. Jr. (2007a). Regulation of life history determines lifespan of worker honey bees (Apis mellifera L.). Exp. Gerontol. 42, 1020-1032.

Rueppell, O., Christine, S., Mulcrone, C., and Groves, L. (2007b). Aging without functional senescence in honey bee workers. Curr. Biol. 17, R274R275.

Rulifson, E. J., Kim, S. K., and Nusse, R. (2002). Ablation of insulinproducing neurons in flies: growth and diabetic phenotypes. Science 296, 1118-1120.

Rutz, W., and Luscher, M. (1974). The occurance of vitellogenin in the workers and queens of Apis mellifica and the possibility of its transmission to the queen. J. Insect Physiol. 20, 897-909.

Sabatino, F., Masoro, E. J., Mcmahan, C. A., and Kuhn, R. W. (1991). Assessment of the role of the glucocorticoid system in aging processes and in the action of food restriction. $J$. Gerontol. 46, B171-B179. 
Salpeter, S. R., Cheng, J., Thabane, L., Buckley, N. S., and Salpeter, E. E. (2009). Bayesian meta-analysis of hormone therapy and mortality in younger postmenopausal women. Am. J. Med. 122, 1016-1022.

Saydah, S., Graubard, B., BallardBarbash, R., and Berrigan, D. (2007). Insulin-like growth factors and subsequent risk of mortality in the United States. Am. J. Epidemiol. 166, 518-526.

Schaap, L. A., Pluijm, S. M., Deeg, D. J., Harris, T. B., Kritchevsky, S. B., Newman, A. B., Colbert, L. H., Pahor, M., Rubin, S. M., Tylavsky, F. A., and Visser, M. (2009). Higher inflammatory marker levels in older persons: associations with 5-year change in muscle mass and muscle strength. $J$. Gerontol. A Biol. Sci. Med. Sci. 64, 1183-1189.

Schaible, R., and Gowen, J. W. (1961). A new dwarf mouse. Genetics 46, 896.

Schneider, H. J., Klotsche, J., Saller, B., Bohler, S., Sievers, C., Pittrow, D., Ruf, G., Marz, W., Erwa, W., Zeiher, A. M., Silber, S., Lehnert, H., Wittchen, H. U., and Stalla, G. K. (2008). Associations of agedependent IGF-I SDS with cardiovascular diseases and risk conditions: cross-sectional study in 6773 primary care patients. Eur. J. Endocrinol. 158, 153-161.

Schneider, S. A., Schrader, C., Wagner, A. E., Boesch-Saadatmandi, C., Liebig, J., Rimbach, G., and Roeder, T. (2011). Stress resistance and longevity are not directly linked to levels of enzymatic antioxidants in the ponerine ant Harpegnathos saltator. PLoS ONE 6, e14601. doi:10.1371/journal.pone.0014601

Selman, C., Lingard, S., Choudhury, A. I., Batterham, R. L., Claret, M., Clements, M., Ramadani, F., Okkenhaug, K., Schuster, E., Blanc, E., Piper, M. D., Al-Qassab, H., Speakman, J. R., Carmignac, D., Robinson, I. C., Thornton, J. M., Gems, D., Partridge, L., and Withers, D. J. (2008). Evidence for lifespan extension and delayed age-related biomarkers in insulin receptor substrate 1 null mice. FASEB J. 22, 807-818.

Selman, C., Phillips, T., Staib, J. L., Duncan, J. S., Leeuwenburgh, C., and Speakman, J. R. (2005). Energy expenditure of calorically restricted rats is higher than predicted from their altered body composition. Mech. Ageing Dev. 126, 783-793.

Seluanov, A., Hine, C., Azpurua, J., Feigenson, M., Bozzella, M., Mao, Z., Catania, K. C., and Gorbunova, V. (2009). Hypersensitivity to contact inhibition provides a clue to cancer resistance of naked mole-rat.
Proc. Natl. Acad. Sci. U.S.A. 106, 19352-19357.

Serrano, R., Villar, M., Gallardo, N., Carrascosa, J. M., Martinez, C., and Andres, A. (2009). The effect of aging on insulin signalling pathway is tissue dependent: central role of adipose tissue in the insulin resistance of aging. Mech. Ageing Dev. 130, 189-197.

Shai, S. Y., Sukhanov, S., Higashi, Y., Vaughn, C., Kelly, J., and Delafontaine, P. (2010). Smooth muscle cell-specific insulin-like growth factor-1 overexpression in Apoe- $/$ mice does not alter atherosclerotic plaque burden but increases features of plaque stability. Arterioscler. Thromb. Vasc. Biol. 30, 1916-1924.

Shai, S. Y., Sukhanov, S., Higashi, Y., Vaughn, C., Rosen, C. J., and Delafontaine, P. (2011). Low circulating insulin-like growth factor I increases atherosclerosis in ApoEdeficient mice. Am. J. Physiol. Heart Circ. Physiol. 300, H1898-H1906.

Shaw, W. M., Luo, S., Landis, J., Ashraf, J., and Murphy, C. T. (2007). The C. elegans TGF-beta Dauer pathway regulates longevity via insulin signaling. Curr. Biol. 17, 1635-1645.

Shevah, O., and Laron, Z. (2007). Patients with congenital deficiency of IGF-I seem protected from the development of malignancies: a preliminary report. Growth Horm. IGF Res. 17, 54-57.

Siminovitch, L., Till, J. E., and Mcculloch, E. A. (1964). Decline in colonyforming ability of marrow cells subjected to serial transplantation into irradiated mice. J. Cell. Physiol. 64, 23-31.

Simon, A. F., Shih, C., Mack, A., and Benzer, S. (2003). Steroid control of longevity in Drosophila melanogaster. Science 299, 1407-1410.

Simonsen, A., Cumming, R. C., Brech, A., Isakson, P., Schubert, D. R., and Finley, K. D. (2008). Promoting basal levels of autophagy in the nervous system enhances longevity and oxidant resistance in adult Drosophila. Autophagy 4, 176-184.

Simonson, D. C., and Defronzo, R. A. (1983). Glucagon physiology and aging: evidence for enhanced hepatic sensitivity. Diabetologia 25, 1-7.

Singh, S. R., Liu, W., and Hou, S. X. (2007). The adult Drosophila malpighian tubules are maintained by multipotent stem cells. Cell Stem Cell 1, 191-203.

Singh, S. R., Zeng, X., Zheng, Z., and Hou, S. X. (2011). The adult Drosophila gastric and stomach organs are maintained by a multipotent stem cell pool at the foregut/midgut junction in the cardia (proventriculus). Cell Cycle 10, 1109-1120.

Skalen, K., Gustafsson, M., Rydberg, E. K., Hulten, L. M., Wiklund, O. Innerarity, T. L., and Boren, J. (2002). Subendothelial retention of atherogenic lipoproteins in early atherosclerosis. Nature 417, 750-754.

Smith, S. R. (1996). The endocrinology of obesity. Endocrinol. Metab. Clin. North Am. 25, 921-942.

Snell, G. D. (1929). Dwarf, a new Mendelian recessive character of the house mouse. Proc. Natl. Acad. Sci. U.S.A. 15, 733-734.

Snowdon, D. A., Kane, R. L., Beeson, W. L., Burke, G. L., Sprafka, J. M., Potter, J., Iso, H., Jacobs, D. R. Jr., and Phillips, R. L. (1989). Is early natural menopause a biologic marker of health and aging? Am. J. Public Health 79, 709-714.

Spagnoli, L. G., Orlandi, A., Mauriello, A., Santeusanio, G., De Angelis, C., Lucreziotti, R., and Ramacci, M. T. (1991). Aging and atherosclerosis in the rabbit. 1. Distribution, prevalence and morphology of atherosclerotic lesions. Atherosclerosis 89, 11-24.

Steger, R. W., Bartke, A., and Cecim, M. (1993). Premature ageing in transgenic mice expressing different growth hormone genes. J. Reprod. Fertil. Suppl. 46, 61-75.

Suh, Y., Atzmon, G., Cho, M. O., Hwang, D., Liu, B., Leahy, D. J., Barzilai, N., and Cohen, P. (2008). Functionally significant insulin-like growth factor I receptor mutations in centenarians. Proc. Natl. Acad. Sci. U.S.A. 105 3438-3442.

Sukhanov, S., Higashi, Y., Shai, S. Y., Vaughn, C., Mohler, J., Li, Y., Song, Y. H., Titterington, J., and Delafontaine, P. (2007). IGF-1 reduces inflammatory responses, suppresses oxidative stress, and decreases atherosclerosis progression in ApoEdeficient mice. Arterioscler. Thromb. Vasc. Biol. 27, 2684-2690.

Sutherland, J. S., Goldberg, G. L., Hammett, M. V., Uldrich, A. P., Berzins, S. P., Heng, T. S., Blazar, B. R., Millar, J. L., Malin, M. A., Chidgey, A. P., and Boyd, R. L. (2005). Activation of thymic regeneration in mice and humans following androgen blockade. J. Immunol. 175, 2741-2753.

Tabas, I., Williams, K. J., and Boren, J. (2007). Subendothelial lipoprotein retention as the initiating process in atherosclerosis: update and therapeutic implications. Circulation 116 , 1832-1844.

Taguchi, A., Wartschow, L. M., and White, M. F. (2007). Brain IRS2 signaling coordinates life span and nutrient homeostasis. Science 317, 369-372.
Taguchi, A., and White, M. F. (2008). Insulin-like signaling, nutrient homeostasis, and life span. Аnпи. Rev. Physiol. 70, 191-212.

Tatar, M. (2004). The neuroendocrine regulation of Drosophila aging. Exp. Gerontol. 39, 1745-1750.

Tatar, M., Chien, S. A., and Priest, N. K. (2001a). Negligible senescence during reproductive dormancy in Drosophila melanogaster. Am. Nat. 158, 248-258.

Tatar, M., Kopelman, A., Epstein, D. Tu, M. P., Yin, C. M., and Garofalo, R. S. (2001b). A mutant Drosophila insulin receptor homolog that extends life-span and impairs neuroendocrine function. Science 292, $107-110$.

Tatar, M., and Yin, C. (2001). Slow aging during insect reproductive diapause: why butterflies, grasshoppers and flies are like worms. Exp. Gerontol. 36, 723-738.

Tattersall, R. B. (1994). CharlesEdouard Brown-Sequard: doublehyphenated neurologist and forgotten father of endocrinology. Diabet. Med. 11, 728-731.

Taub, D. D., and Longo, D. L. (2005). Insights into thymic aging and regeneration. Immunol. Rev. 205, 72-93.

Tazearslan, C., Huang, J., Barzilai, N., and Suh, Y. (2011). Impaired IGF1R signaling in cells expressing longevity-associated human IGF1R alleles. Aging Cell 10, 551-554.

Tenover, J. S. (1994). Androgen administration to aging men. Endocrinol. Metab. Clin. North Am. 23, 877-892.

Terzibasi, E., Valenzano, D. R., Benedetti, M., Roncaglia, P., Cattaneo, A., Domenici, L., and Cellerino, A. (2008). Large differences in aging phenotype between strains of the shortlived annual fish Nothobranchius furzeri. PLoS ONE 3, e3866. doi:10.1371/journal.pone.0003866

Thummel, C. S. (1996). Flies on steroids-Drosophila metamorphosis and the mechanisms of steroid hormone action. Trends Genet. 12, 306-310.

Tran, H., Brunet, A., Grenier, J. M., Datta, S. R., Fornace, A. J. Jr., Distefano, P. S., Chiang, L. W., and Greenberg, M.E. (2002). DNA repair pathway stimulated by the forkhead transcription factor FOXO3a through the Gadd45 protein. Science 296, 530-534.

Tricoire, H., Battisti, V., Trannoy, S., Lasbleiz, C., Pret, A. M., and Monnier, V. (2009). The steroid hormone receptor EcR finely modulates Drosophile lifespan during adulthood in a sexspecific manner. Mech. Ageing Dev. 130, 547-552. 
Tu, M. P., Epstein, D., and Tatar, M. (2002a). The demography of slow aging in male and female Drosophila mutant for the insulin-receptor substrate homologue chico. Aging Cell 1, 75-80.

Tu, M. P., Yin, C. M., and Tatar, M. (2002b). Impaired ovarian ecdysone synthesis of Drosophila melanogaster insulin receptor mutants. Aging Cell 1, 158-160.

Tu, M. P., Yin, C. M., and Tatar, M. (2005). Mutations in insulin signaling pathway alter juvenile hormone synthesis in Drosophila melanogaster. Gen. Comp. Endocrinol. 142, 347-356.

Ueyama, M., and Fuyama, Y. (2003). Enhanced cost of mating in female sterile mutants of Drosophila melanogaster. Genes Genet. Syst. 78, 29-36.

Utsuyama, M., and Hirokawa, K. (1989). Hypertrophy of the thymus and restoration of immune functions in mice and rats by gonadectomy. Mech. Ageing Dev. 47, 175-185.

Vaessen, N., Heutink, P., Janssen, J. A., Witteman, J. C., Testers, L., Hofman, A., Lamberts, S. W., Oostra, B. A., Pols, H. A., and Van Duijn, C. M. (2001). A polymorphism in the gene for IGF-I: functional properties and risk for type 2 diabetes and myocardial infarction. Diabetes 50, 637-642.

Valdesalici, S., and Cellerino, A. (2003). Extremely short lifespan in the annual fish Nothobranchius furzeri. Proc. Biol. Sci. 270(Suppl. 2), S189S191.

Vallejo, A. N., Michel, J. J., Bale, L. K., Lemster, B. H., Borghesi, L., and Conover, C. A. (2009). Resistance to age-dependent thymic atrophy in long-lived mice that are deficient in pregnancy-associated plasma protein A. Proc. Natl. Acad. Sci. U.S.A. 106, 11252-11257.

Van Bunderen, C. C., Van Nieuwpoort, I. C., Van Schoor, N. M., Deeg, D. J., Lips, P., and Drent, M. L. (2010). The association of serum insulinlike growth factor-I with mortality, cardiovascular disease, and cancer in the elderly: a population-based study. J. Clin. Endocrinol. Metab. 95, 4616-4624.

Van Cauter, E., Leproult, R., and Kupfer, D. J. (1996). Effects of gender and age on the levels and circadian rhythmicity of plasma cortisol. J. Clin. Endocrinol. Metab. 81, 2468-2473.

Van Heemst, D., Beekman, M., Mooijaart, S. P., Heijmans, B. T., Brandt, B. W., Zwaan, B. J., Slagboom, P. E., and Westendorp, R. G. (2005). Reduced insulin/IGF-1 signalling and human longevity. Aging Cell 4, 79-85.
Vasan, R. S., Sullivan, L. M., D’Agostino, R. B., Roubenoff, R., Harris, T., Sawyer, D. B., Levy, D., and Wilson, P. W. (2003). Serum insulin-like growth factor I and risk for heart failure in elderly individuals without a previous myocardial infarction: the Framingham Heart Study. Ann. Intern. Med. 139, 642-648.

Vasile, E., Simionescu, M., and Simionescu, N. (1983). Visualization of the binding, endocytosis, and transcytosis of low-density lipoprotein in the arterial endothelium in situ. J. Cell Biol. 96, 1677-1689.

Veldhuis, J. D., Erickson, D., Iranmanesh, A., Miles, J. M., and Bowers, C. Y. (2005). Sex-steroid control of the aging somatotropic axis. Endocrinol. Metab. Clin. North Am. 34, 877-893.

Vergara, M., Smith-Wheelock, M., Harper, J. M., Sigler, R., and Miller, R. A. (2004). Hormone-treated snell dwarf mice regain fertility but remain long lived and disease resistant. J. Gerontol. A Biol. Sci. Med. Sci. 59, 1244-1250.

Virmani, R., Avolio, A. P., Mergner, W. J., Robinowitz, M., Herderick, E. E., Cornhill, J. F., Guo, S. Y., Liu, T. H., Ou, D. Y., and O'Rourke, M. (1991). Effect of aging on aortic morphology in populations with high and low prevalence of hypertension and atherosclerosis. Comparison between occidental and Chinese communities. Am. J. Pathol. 139, 1119-1129.

Visser, M., Pahor, M., Taaffe, D. R. Goodpaster, B. H., Simonsick, E. M., Newman, A. B., Nevitt, M., and Harris, T. B. (2002). Relationship of interleukin- 6 and tumor necrosis factor-alpha with muscle mass and muscle strength in elderly men and women: the Health ABC Study. J. Gerontol. A Biol. Sci. Med. Sci. 57, M326-M332.

Voog, J., D’Alterio, C., and Jones, D. L. (2008). Multipotent somatic stem cells contribute to the stem cell niche in the Drosophila testis. Nature 454, 1132-1136.

Walford, R. L., Mock, D., Verdery, R., and Maccallum, T. (2002). Calorie restriction in biosphere 2: alterations in physiologic, hematologic, hormonal, and biochemical parameters in humans restricted for a 2-year period. J. Gerontol. A Biol. Sci. Med. Sci. 57, B211-B224.

Walkiewicz, M. A., and Stern, M. (2009). Increased insulin/insulin growth factor signaling advances the onset of metamorphosis in Drosophila. PLoS ONE 4, e5072. doi:10.1371/journal.pone.0005072

Wang, J., Niu, W., Nikiforov, Y., Naito, S., Chernausek, S., Witte, D., Leroith,
D., Strauch, A., and Fagin, J. A. (1997). Targeted overexpression of IGF-I evokes distinct patterns of organ remodeling in smooth muscle cell tissue beds of transgenic mice. $J$. Clin. Invest. 100, 1425-1439.

Wang, M., Takagi, G., Asai, K., Resuello, R. G., Natividad, F. F., Vatner, D. E., Vatner, S. F., and Lakatta, E. G. (2003). Aging increases aortic MMP2 activity and angiotensin II in nonhuman primates. Hypertension 41, 1308-1316.

Wang, M., Zhang, J., Jiang, L. Q., Spinetti, G., Pintus, G., Monticone, R., Kolodgie, F. D., Virmani, R., and Lakatta, E. G. (2007a). Proinflammatory profile within the grossly normal aged human aortic wall Hypertension 50, 219-227.

Wang, S., Tulina, N., Carlin, D. L., and Rulifson, E. J. (2007b). The origin of islet-like cells in Drosophila identifies parallels to the vertebrate endocrine axis. Proc. Natl. Acad. Sci. U.S.A. 104, 19873-19878.

Wang, M., Zhang, J., Spinetti, G., Jiang, L. Q., Monticone, R., Zhao, D., Cheng, L., Krawczyk, M., Talan, M., Pintus, G., and Lakatta, E. G. (2005). Angiotensin II activates matrix metalloproteinase type II and mimics age-associated carotid arterial remodeling in young rats. Am. J. Pathol. 167, 1429-1442.

Wang, Y., and Sun, Z. (2009). Current understanding of klotho. Ageing Res. Rev. 8, 43-51.

Waterstrat, A., and Van Zant, G. (2009). Effects of aging on hematopoietic stem and progenitor cells. Curr Opin. Immunol. 21, 408-413.

Wei, J., Xu, H., Davies, J. L., and Hemmings, G. P. (1992). Increase of plasma IL-6 concentration with age in healthy subjects. Life Sci. 51, 1953-1956.

Weindruch, R., and Walford, R. L. (1982). Dietary restriction in mice beginning at 1 year of age: effect on life-span and spontaneous cancer incidence. Science 215 1415-1418.

Weindruch, R., Walford, R. L., Fligiel, S. and Guthrie, D. (1986). The retardation of aging in mice by dietary restriction: longevity, cancer, immunity and lifetime energy intake. $J$. Nutr. 116, 641-654.

Weiss, E. P., Racette, S. B., Villareal, D. T. Fontana, L., Steger-May, K., Schechtman, K. B., Klein, S., and Holloszy, J. O. (2006). Improvements in glucose tolerance and insulin action induced by increasing energy expenditure or decreasing energy intake: a randomized controlled trial. Am. J. Clin. Nutr. 84, 1033-1042.

Weiss, E. P., Villareal, D. T., Fontana, L., Han, D. H., and Holloszy, J. O.
(2011). Dehydroepiandrosterone (DHEA) replacement decreases insulin resistance and lowers inflammatory cytokines in aging humans. Aging 3, 533-542.

Wigby, S., and Chapman, T. (2005). Sex peptide causes mating costs in female Drosophila melanogaster. Curr. Biol. 15, 316-321.

Willcox, B. J., Donlon, T. A., He, Q., Chen, R., Grove, J. S., Yano, K., Masaki, K. H., Willcox, D. C., Rodriguez, B., and Curb, J. D. (2008). FOXO3A genotype is strongly associated with human longevity. Proc. Natl. Acad. Sci. U.S.A. 105, 13987-13992.

Wolkow, C. A., Kimura, K. D., Lee, M. S. and Ruvkun, G. (2000). Regulation of C. elegans life-span by insulinlike signaling in the nervous system. Science 290, 147-150.

Wu, D., Ren, Z., Pae, M., Guo, W., Cui, X., Merrill, A. H., and Meydani, S. N. (2007). Aging up-regulates expression of inflammatory mediators in mouse adipose tissue. J. Immunol. 179, 4829-4839.

Wyllie, A. H. (1980). Glucocorticoidinduced thymocyte apoptosis is associated with endogenous endonuclease activation. Nature 284, 555-556.

Xu, H., Barnes, G. T., Yang, Q., Tan, G., Yang, D., Chou, C. J., Sole, J., Nichols, A., Ross, J. S., Tartaglia, L. A., and Chen, H. (2003). Chronic inflammation in fat plays a crucial role in the development of obesity-related insulin resistance. J. Clin. Invest. 112, 1821-1830.

Xu, J., Kochanek, K. D., Murphy, S. L. and Tejada-Vera, B. (2010). National Vital Statistics Report. Hyattsville, MD: N.C.F.H. Statistics.

Yakar, S., Liu, J. L., Stannard, B., Butler, A., Accili, D., Sauer, B., and Leroith, D. (1999). Normal growth and development in the absence of hepatic insulin-like growth factor I. Proc. Natl. Acad. Sci. U.S.A. 96, 7324-7329.

Yamawaki, T. M., Arantes-Oliveira, N., Berman, J. R., Zhang, P., and Kenyon, C. (2008). Distinct activities of the germline and somatic reproductive tissues in the regulation of Caenorhabditis elegans' longevity. Genetics 178, 513-526.

Yamawaki, T. M., Berman, J. R., Suchanek-Kavipurapu, M., Mccormick, M., Gaglia, M. M., Lee, S. J., and Kenyon, C. (2010). The somatic reproductive tissues of $C$. elegans promote longevity through steroid hormone signaling. PLoS Biol. 8, e1000468. doi:10.1371/journal.pbio. 1000468 
Yeap, B. B., Chubb, S. A., Mccaul, K. A., Ho, K. K., Hankey, G. J., Norman, P. E., and Flicker, L. (2011). Associations of IGF1 and IGFBPs 1 and 3 with all-cause and cardiovascular mortality in older men: the Health in Men Study. Eur. J. Endocrinol. 164, 715-723.

Yu, H., Spitz, M. R., Mistry, J., Gu, J., Hong, W. K., and $\mathrm{Wu}, \mathrm{X}$. (1999). Plasma levels of insulinlike growth factor-I and lung cancer risk: a case-control analysis. J. Natl. Cancer Inst. 91, 151-156.

Zaina, S., Pettersson, L., Ahren, B., Branen, L., Hassan, A. B., Lindholm, M., Mattsson, R., Thyberg, J., and Nilsson, J. (2002). Insulinlike growth factor II plays a central role in atherosclerosis in a mouse model. J. Biol. Chem. 277, 4505-4511.
Zaina, S., Pettersson, L., Thomsen, A. B., Chai, C. M., Qi, Z., Thyberg, J., and Nilsson, J. (2003). Shortened life span, bradycardia, and hypotension in mice with targeted expression of an Igf2 transgene in smooth muscle cells. Endocrinology 144, 2695-2703.

Zhang, M., Smith, E. P., Kuroda, H., Banach, W., Chernausek, S. D., and Fagin, J. A. (2002). Targeted expression of a protease-resistant IGFBP4 mutant in smooth muscle of transgenic mice results in IGFBP4 stabilization and smooth muscle hypotrophy. J. Biol. Chem. 277, 21285-21290.

Zhang, S. H., Reddick, R. L., Piedrahita, J. A., and Maeda, N. (1992). Spontaneous hypercholesterolemia and arterial lesions in mice lacking apolipoprotein E. Science 258, 468-471.
Zhou, Y., Xu, B. C., Maheshwari, H. G., He, L., Reed, M., Lozykowski, M., Okada, S., Cataldo, L., Coschigamo, K., Wagner, T. E., Baumann, G., and Kopchick, J. J. (1997). A mammalian model for Laron syndrome produced by targeted disruption of the mouse growth hormone receptor/binding protein gene (the Laron mouse). Proc. Natl. Acad. Sci. U.S.A. 94, 13215-13220.

Zhou, Z., Akinbiyi, T., Xu, L., Ramcharan, M., Leong, D. J., Ros, S. J., Colvin, A. C., Schaffler, M. B., Majeska, R. J., Flatow, E. L., and Sun, H. B. (2010). Tendon-derived stem/progenitor cell aging: defective self-renewal and altered fate. Aging Cell 9, 911-915].

Conflict of Interest Statement: The authors declare that the research was conducted in the absence of any commercial or financial relationships that could be construed as a potential conflict of interest.

Received: 31 August 2011; accepted: 28 October 2011; published online: 23 November 2011.

Citation: Allard JB and Duan C (2011) Comparative endocrinology of aging and longevity regulation. Front. Endocrin. 2:75. doi: 10.3389/fendo.2011.00075

This article was submitted to Frontiers in Experimental Endocrinology, a specialty of Frontiers in Endocrinology.

Copyright $\odot 2011$ Allard and Duan. This is an open-access article subject to a nonexclusive license between the authors and Frontiers Media SA, which permits use, distribution and reproduction in other forums, provided the original authors and source are credited and other Frontiers conditions are complied with. 